\title{
Advanced epithelial lung and gut barrier models demonstrate passage of microplastic particles
}

Joanne M. Donkers ${ }^{1 *}$ (D), Elena M. Höppener ${ }^{2}$, Ilya Grigoriev ${ }^{3}$, Lena Will ${ }^{3}$, Barbro N. Melgert ${ }^{4,5}$, Bas van der Zaan ${ }^{6}$, Evita van de Steeg ${ }^{1+}$ and Ingeborg M. Kooter ${ }^{2+}$

\begin{abstract}
Micro- and nanoplastics (MNP) can be found virtually everywhere around us in the biosphere and food chain, therefore humans are continuously exposed to MNP, mainly via inhalation and ingestion. Here, we have applied physiologically relevant human-based advanced in vitro models representing the lung (MucilAir ${ }^{\mathrm{TM}}$ ) and gut (InTESTine ${ }^{\text {TM }}$ and Intestinal Explant Barrier Chip (IEBC)) to study membrane passage of various MNP and their potency to induce cytotoxic effects, barrier disturbances or pro-inflammatory cell activation. Selected MNP of various materials (polystyrene, polyethylene, nylon, car tire, and marine MNP collected from the ocean), shapes (spheres, fragments and fibers), sizes $(0.05-100 \mu \mathrm{m})$, some of which were fluorescently labelled for tracking, were included. Without affecting cell viability, nylon fibers and (cleaned) HDPE (high density polyethylene) disrupted the MucilAir $^{\mathrm{TM}}$ epithelial barrier. Luminal exposure to polystyrene particles ( 1 and $\left.10 \mu \mathrm{m}\right)$ and pristine HDPE fragments significantly decreased human colon tissue functionality. Furthermore, all polystyrene particles $(0.05,1$ and $10 \mu \mathrm{m})$ affected tissue viability in porcine jejunum, ileum and colon tissue after $5 \mathrm{~h}$ exposure, and this was further confirmed in the IEBC after $24 \mathrm{~h}$ of exposure to $10 \mu \mathrm{m}$ polystyrene particles and nylon fibers. Exposure to nylon fibers and its supernatant led to pro-inflammatory cell activation, as shown by increased IL-6 release in MucilAir ${ }^{\text {TM }}$ and in human colon tissue after 96 or $24 \mathrm{~h}$, respectively. Regarding transepithelial penetration of the MNP, permeability of $0.05 \mu \mathrm{m}$ polystyrene spheres in the MucilAir ${ }^{\text {TM }}$ lung cell model reached $3.6 \pm 1.2 \%$ after $24 \mathrm{~h}$. With $3.37 \pm 0.46 \%$ after $5 \mathrm{~h}$ under static conditions and $5.5 \pm 1.3 \%$ after $24 \mathrm{~h}$ under microfluidic conditions MNP permeability across intestinal tissue was highest for the largest $(10 \mu \mathrm{m})$ polystyrene spheres. Confocal microscopy confirmed the translocation of MNP across the lung and intestinal epithelial barrier. In conclusion, we present a study revealing the passage of MNP over the epithelium of advanced in vitro models for the lung and intestine barrier. Furthermore, pro-inflammatory cell activation and disrupted barrier integrity were observed after exposure to several of the tested MNP. Future research is needed to further identify the effects of shape, size and material on these processes and subsequently the health effects of humans.
\end{abstract}

Keywords: Microplastics, In vitro, Membrane passage, Lung epithelium, Intestinal tissue

\footnotetext{
* Correspondence: joanne.donkers@tno.nl

${ }^{\dagger}$ Evita van de Steeg and Ingeborg M. Kooter contributed equally to this work.

'Department of Metabolic Health Research, the Netherlands Organization for

Applied Scientific Research (TNO), Zeist, The Netherlands

Full list of author information is available at the end of the article
}

\section{Springer Open}

( ) The Author(s). 2021 Open Access This article is licensed under a Creative Commons Attribution 4.0 International License, which permits use, sharing, adaptation, distribution and reproduction in any medium or format, as long as you give appropriate credit to the original author(s) and the source, provide a link to the Creative Commons licence, and indicate if changes were made. The images or other third party material in this article are included in the article's Creative Commons licence, unless indicated otherwise in a credit line to the material. If material is not included in the article's Creative Commons licence and your intended use is not permitted by statutory regulation or exceeds the permitted use, you will need to obtain permission directly from the copyright holder. To view a copy of this licence, visit http://creativecommons.org/licenses/by/4.0/. 


\section{Introduction}

Nowadays, one cannot imagine a life without plastics because of their countless benefits and ubiquitous applications such as in food wrapping, bottling, toys, medical applications, textile industry and tire production. With an annual global production of 359 million tonnes in 2018, plastic is the third most abundant man-made material after steel and concrete [1]. However, one of the major advances of plastics might also be their problem, namely that they are persistent and degrade very slowly [2]. Plastic fragments with a size less than $5 \mathrm{~mm}$ are defined as microplastics [3], which also include plastic particles in the nanoscale size. This latter group of very small particles $(\leq 100 \mathrm{~nm})$ are also specifically referred to as nanoplastics $[3,4]$. Here, we are referring to both micro- and nano-sized particles, and use the term microand nanoplastics (MNP) throughout the manuscript.

MNP can be found virtually everywhere in the biosphere and food chain [5-12]. MNP are either intentionally added to products (e.g. in cosmetics, cleaning products, medical applications), or have fragmented and degraded from larger plastic items such as plastic waste, tires, textile etc. MNP are released into the environment: transported into seas, carried into the air and come down with rain [13]. The large volumes of plastics released into the environment over the last decades have caused ubiquitous microplastic pollution on a global level. Whilst evidence that microplastic pollution poses widespread risks to humans or the environment is lacking, scientists predict that, if emissions of plastics into the environment continue at the current rate or increase, ecological risks could be widespread within a century and the health of humans could potentially also be at risk [14-16]. Given the potential concerns for the predicted release of MNP into the environment in the coming years, in combination with the uncertain ecological and human health risks, there is a need to generate robust data aimed at better understanding both the exposure and potential effects that MNP may cause in humans.

The main exposure routes of MNP for humans, as other pollutants, are via inhalation, ingestion and to a lesser extend dermal absorption [16, 17]. Recently, MNP have been detected in human placenta [18]. In addition several MNP have been detected in human stool samples, suggesting unintended ingestion from different sources [19]. There are currently only a few studies known where they have investigated the in vitro absorption (and potential cytotoxic effects) of MNP across lung and intestinal epithelium [20, 21]. In these studies simple single cell-based assays such as A594 cells (lung) or Caco-2 cells (gut) have been applied. However, the predictive value of these methods is often insufficient due to lack of physiological complexity of the lung epithelial tissue and gastrointestinal tract. Here, we aimed to study membrane passage of various MNP and their potency to induce cytotoxic effects, barrier disturbances or immune response by applying physiologically relevant human-based models representing the lung and gut epithelial barrier. The applied models include Muci1 Air ${ }^{\mathrm{rn}}$, a 3D reconstructed human airway model of the bronchial epithelium $[22,23]$ and InTESTine ${ }^{\mathrm{Tm}}$, a human tissue based explant model $[24,25]$. Based on this first set of preliminary data we provide evidence that a fraction of the inadvertent inhaled or ingested MNP, administered as a relatively high acute single dose, is able to pass the epithelial barrier of lung and gut, thereby amenable to potentially causing subsequent health effects in secondary organs (e.g. liver, kidney, brain). Furthermore, exposure to several of the tested MNP led to a pro-inflammatory cell activation and detrimental effects on barrier integrity. These observations together justify the need for research to develop and apply advanced in vitro models, such as the models presented here, in order to strengthen qualitative and quantitative in vitro in vivo extrapolation of data to improve human health risk assessment upon MNP exposure.

\section{Methods}

Applied micro- and nanoplastics

The following MNP were used: Fluoro-Max Dyed Green Aqueous Fluorescent Particles of $0.05 \mu \mathrm{m}$ (G50), $1 \mu \mathrm{m}$ (G0100) and $10 \mu \mathrm{m}$ (CDG1000) were purchased from ThermoFisher Scientific, polystyrene particles (PS) of $0.05 \mu \mathrm{m}, 0.1 \mu \mathrm{m}, 1 \mu \mathrm{m}, 10 \mu \mathrm{m}$ (purchased from PolySciences and washed with PBS) and high density polyethylene (HDPE) were kindly provided by Deltares (Delft, the Netherlands). HDPE was washed with hexane to obtain the so-called HDPE-cleaned. Nylon 6,6 fibers $3 \times 13 \mu \mathrm{m}$ and $10 \times 30 \mu \mathrm{m}$ were kindly provided by the Rijksuniversiteit Groningen (RUG, Groningen, the Netherlands) who purchased the materials from Goodfellow (product number AM325705). At RUG they harvested the nylon supernatant of the $10 \times 30$ fibers by suspending the microfibers in water for 7 days at $37^{\circ} \mathrm{C}$ after which the suspension was filtered over a $0.2 \mu \mathrm{m}$ filter to obtain the supernatant. Car tire particles were generated in-house by cryogenic milling of a car tire (Goodyear 155/70 R13 75S) provided by a recycling center and subsequently sieving these particles over a $120 \mu \mathrm{m}$ stainless steel sieve. Marine MNP were provided as a mixtures of $\mathrm{mm}$ sized (weathered) plastic particles by The Ocean Cleanup (Rotterdam, the Netherlands). These particles were further cryomilled in-house and subsequently sieved over a $40 \mu \mathrm{m}$ stainless steel sieve. 


\section{Chemicals and assay buffer}

$\left[{ }^{14} \mathrm{C}\right]$ caffeine and $\left[{ }^{3} \mathrm{H}\right]$ mannitol were purchased from Perkin Elmer Inc. Fluorescein isothiocyanate-dextran with a molecular weight of $4000 \mathrm{Da}$ (FD4) and Cytotoxicity Detection Kit ${ }^{\mathrm{PLUS}}$ to measure LDH were obtained from Sigma-Aldrich B.V. Components of the so-called 'cytomix' were TNF- $\alpha$ (210-TA-005, R\&D systems), LPS (L2630-10, Sigma-Aldrich), and fetal calf serum (FCS) (10270-106, lot: 2166469, Gibco). The following antibodies were used: anti-phalloidin Alexa568 (ThermoFisher, A12380), anti-acetylated tubulin IgG2 (SigmaAldrich, T7451), anti-mouse Alexa647 (Life Technologies, A21236), anti-mouse IgG2b Alexa647 (Life Technologies, A21242). Vectashield ${ }^{\circ}$ antifade mounting medium with DAPI (H-1200-10) was obtained from Vector Laboratories. Williams E buffer was used according to Stevens et al. [25], supplemented with $25 \mathrm{mM} \mathrm{d}-$ glucose, $10 \mathrm{~mL} / \mathrm{L}$ Glutamax and $10 \mathrm{~mL} / \mathrm{L}$ HEPES, gentamycin $50 \mu \mathrm{g} / \mathrm{mL}$, amphotericin $25 \mu \mathrm{g} / \mathrm{mL}$ and stored at $2-10{ }^{\circ} \mathrm{C}$ until use. Williams $\mathrm{E}$ supplemented with $1 \%$ and $4 \%$ BSA was used to precoat the plates or microfluidic system and in the basolateral compartment during an experiment, respectively.

\section{Human and porcine intestinal tissue}

Human intestinal colon tissue was obtained from $1 \mathrm{hu}$ man adult patient undergoing surgery for colon carcinoma. Ethical approval for the use of human intestinal tissue was provided by the hospital board. Prior to surgery, informed consent was asked from the patient. After dissection of the intestinal tissue, the healthy considered tissue, examined by the surgeon or pathologist, was donated for research purposes. Porcine jejunum, ileum and colon tissue for the InTESTine ${ }^{\mathrm{TM}}$ experiment was obtained from 1 domestic pig $(15-25 \mathrm{~kg})$ used for educational purposes at the Utrecht University (Utrecht, the Netherlands). Porcine colon tissue for the Intestinal Explant Barrier Chip experiment was obtained from 1 domestic adult pig at a local slaughterhouse. Tissue was collected within $10 \mathrm{~min}$ of the death of an animal and immediately flushed with ice cold supplemented Williams E buffer to remove fecal content. During transportation and preparation in the lab, the tissue was placed in ice cold supplemented Williams E buffer. At the laboratory, fat tissue and the musculo-serosal layer of the mucosal layer was dissected off and round segments of $0.246 \mathrm{~cm}^{2}$ (for InTESTine $\mathrm{e}^{\mathrm{mw}}$ ) or $0.968 \mathrm{~cm}^{2}$ (for Intestinal Explant Barrier Chip) were punched.

\section{MucilAir $^{\mathrm{TM}}$}

MucilAir $^{\text {na }}$ inserts and medium were obtained from Epithelix and placed in a humidified incubator at $37^{\circ} \mathrm{C}$ with $5 \% \mathrm{CO}_{2}$. Until exposure to the MNP, the basolateral medium was refreshed every $2-3$ days. On the day of the experiment, inserts were washed at both sides with $0.9 \%$ saline containing $1.25 \mathrm{mM} \mathrm{CaCl}_{2}$ and $0.1 \mathrm{M}$ HEPES. Thereafter, the inserts were placed in fresh basolateral medium and apically exposed to $50 \mu \mathrm{L} \mathrm{MNP}$ suspension $(1 \mathrm{mg} / \mathrm{mL}), 0.1 \%$ Triton X-100 or cytomix (500 ng/mL TNF- $\alpha, 0.2 \mathrm{mg} / \mathrm{mL}$ LPS, $1 \%$ FCS), prepared in $20 \%$ MucilAir $^{\text {Tix }}$ medium in sterile water supplemented with pen/strep $(100 \mathrm{U} / \mathrm{mL})$ and fungizone $(2.5 \mu \mathrm{g} / \mathrm{mL})$, for 24-96h. Upon exposure for $96 \mathrm{~h}$, the inserts were washed with the saline-CaCl -HEPES solution after $48 \mathrm{~h}$ and subsequently received fresh MNP suspension or medium at the apical or basolateral side, respectively. Transepithelial electrical resistance (TEER) was measured using a Millicell-ERS epithelial volt-ohmmeter at the moment of washing both sides of the inserts with the saline- $\mathrm{CaCl}_{2}$-HEPES solution. At the end of an experiment, inserts were washed with the saline- $\mathrm{CaCl}_{2}$ HEPES solution, the membranes containing the cells were cut out of their holder, snap frozen and stored at $-80{ }^{\circ} \mathrm{C}$ until further analysis.

\section{InTESTine ${ }^{\mathrm{TM}}$}

The InTESTine ${ }^{\mathrm{m} u}$ system suitable for a 24 -well plate was used as described previously [25]. Briefly, on the day of the experiment, all media and dosing solutions were placed in a water bath at $37{ }^{\circ} \mathrm{C}$. MNP solutions were prepared at $1 \mathrm{mg} / \mathrm{mL}$. With the mucosal side of the ex vivo intestinal segment facing upwards, the device was placed horizontally into the basolateral compartment which contained $0.875 \mathrm{~mL}$ of ice-cold Williams $\mathrm{E}$ medium and the apical compartment contained $125 \mu \mathrm{L}$ of Williams E medium. Thereafter, the system was placed into a humidified incubator at $37^{\circ} \mathrm{C}$ with $95 \% \mathrm{O}_{2}, 5 \% \mathrm{CO}_{2}$ for preincubation and to slowly warm-up to $37^{\circ} \mathrm{C}$ for a period of $30 \mathrm{~min}$. After pre-incubation, the basolateral Williams E medium was replaced by prewarmed Williams E medium containing $4 \%$ BSA. The apical buffer was removed and mucus build up during the preincubation phase was aspirated off. Afterwards, Williams E medium containing the compound of interest was added at the apical side. The system was placed in the humidified incubator again for 4 or $5 \mathrm{~h}$. During the incubation, the system was placed on a rocker platform, gently shaking the plates at $200 \mathrm{rpm}$. Apical and basolateral samples were taken at regular time intervals, and replaced by new apical and basolateral solutions. At the end of an experiment, the ex vivo segment was dismounted and washed three times in ice-cold Williams $\mathrm{E}$ medium to remove nonspecifically bound compound. Afterwards, the tissue segments were snap frozen and stored at $-80^{\circ} \mathrm{C}$ until further analysis. 


\section{Intestinal explant barrier Chip (IEBC)}

The design and fabrication of the Intestinal Explant Barrier Chip is described by Eslami Amirabadi and Donkers et al., 2021 [26]. One day before the experiment, all media and dosing solutions were placed in a humidified incubator at $37^{\circ} \mathrm{C}$ with $5 \% \mathrm{CO}_{2}$. The microfluidic system and Intestinal Explant Barrier Chips were prepared one day prior to an experiment. After connecting the individual compartments with tubing, reservoirs were filled and the system was subsequently flushed with $20 \%$ biofilm (Umwletanalytik) and PBS. Next, Williams E supplemented with $1 \%$ BSA was added for overnight incubation in a humidified incubator at $37^{\circ} \mathrm{C}$ with $5 \%$ $\mathrm{CO}_{2}$. Flow rates of 2 and $20 \mathrm{~mL} / \mathrm{h}$ were used for overnight incubation and flushing, respectively. The next day, systems were transferred to a working bench. $1 \mathrm{~mm}$ thick EPDM rubber rings (Eriks), intestinal tissue segments (mucosal side upwards) on a woven mesh of $170 \mu \mathrm{m}$ in thickness and 50\% open area (Nitex, Sefar) and a fixing insert were clicked in the snap fit mechanism, thereby separating the apical and basolateral compartments of the microfluidic chip. Subsequently, the Williams E supplemented with 1\% BSA was replaced by the apical and basolateral media: Williams E supplemented with FD4 and compounds or Williams E supplemented with $4 \%$ BSA, respectively. Thereafter, the system was placed back in the incubator and perfused at $2 \mathrm{~mL} / \mathrm{h}$. Apical and basolateral samples were collected from the medium reservoirs, during which the peristaltic pump was stopped briefly. At $\mathrm{t}=20 \mathrm{~h}$, apical and basolateral media were replaced with fresh media. At the end of the experiment, systems were removed from the incubator and all media were replaced with PBS. Next, the tissue segments were removed from the Intestinal Explant Barrier Chips and collected for subsequent analyses. Tubings, chips and reservoirs were flushed and washed with $20 \%$ biofilm and $70 \%$ ethanol.

\section{Intestinal tissue permeability measurements}

$\left[{ }^{3} \mathrm{H}\right]$ mannitol (low permeability) and $\left[{ }^{14} \mathrm{C}\right]$ caffeine (high permeability) were used as reference markers for the paracellular and transcellular transport route, respectively. $\left[{ }^{3} \mathrm{H}\right]$ mannitol and $\left[{ }^{14} \mathrm{C}\right]$ caffeine were mixed with non-radiolabeled mannitol and caffeine, respectively, to obtain final nominal concentrations of $10 \mu \mathrm{M}$ in the apical solution with an associated radioactivity of 10 and 1 $\mathrm{kBq} / \mathrm{mL}$, respectively. Transport was measured by taking apical $\left(40 \mu \mathrm{L}\right.$ for InTESTine ${ }^{\mathrm{Tw}}, 100 \mu \mathrm{L}$ for IEBC) and basolateral $(500 \mu \mathrm{L})$ samples at indicated timepoints. Radioactive labelled compounds were measured using the Tri-Carb 3100TR Liquid Scintillation counter (LSC, Perkin Elmer, Boston Massachusetts, United States) after adding scintillation liquid (Ultima Gold, Perkin Elmer Inc., Boston, Massachusetts, United States) to the apical and basolateral samples. Apical-to-basolateral transport was calculated based on the following equation:

$$
P_{a p p}=\frac{d Q / d t}{A \times C_{a p i, 0}}
$$

$\mathrm{P}_{\text {app }}(\mathrm{cm} / \mathrm{s})$ denotes the apparent permeability coefficient, $\mathrm{dQ} / \mathrm{dt}$ indicates the appearance rate of the compound at the basolateral side over time, $\mathrm{A}$ is the surface area of the exposed tissue and $C_{a p i, 0}$ is the initial dose concentration of the compound. The transcellular over paracellular $\mathrm{P}_{\text {app }}$ ratio was calculated as $\mathrm{P}_{\text {app }}$ caffeine/ $\mathrm{P}_{\text {app }}$ mannitol.

\section{Tissue viability measurements}

To assess the viability of the ex vivo intestinal segments, the cytosolic enzyme lactate dehydrogenase (LDH) was measured in the apical and basolateral supernatants using an LDH kit (Sigma-Aldrich) as previously used $[24,25]$. Intracellular LDH levels were measured with the same kit, after homogenizing the tissue segments in ice-cold Williams E buffer using a gentleMACS ${ }^{\mathrm{Th}}$ Dissociator. Excreted LDH levels were expressed as percentage leakage of the total intracellular LDH of a blanc intestinal tissue segment which was collected before incubation. Samples were analyzed using the BioTek Synergy HT microplate reader (BioTek Instruments Inc., Winooski, VT) with an excitation/emission wavelength of $490 \mathrm{~nm}$ and $520 \mathrm{~nm}$. The acceptance criterion for this parameter is leakage $<3 \%$ per hour of total LDH under control conditions.

\section{Tissue integrity and fluorescent MNP measurements}

To assess the barrier integrity of the tissue, every incubation, except incubations with fluorescent MNP, was coincubated with FITC Dextran 4000 (FD4) and leakage of FD4 from the apical to basolateral compartment was determined. FD4 was analyzed using a BioTek Synergy HT microplate reader (BioTek Instruments Inc., Winooski, VT) with an excitation/emission wavelength of $485 \mathrm{~nm}$ and $528 \mathrm{~nm}$. The acceptance criterion for this parameter is FD4 leakage $<1 \%$ per hour under control conditions. Transport of fluorescently labeled MNP from the apical to basolateral compartment was determined using the same reader and settings.

\section{Determination of the cytokine secretion}

After 24 (IEBC) and $96 \mathrm{~h}$ (MucilAir ${ }^{\mathrm{ru}}$ ) of incubation, samples were taken to assess cytokine secretion into the basolateral compartment. MucilAir ${ }^{\mathrm{Tm}}$ cytokine IL-6 and IL-8 secretion was measured with ELISA (Invitrogen, Carlsbad, US) according to manufacturer's instructions. IL-6, IL-8, IL-1 $\beta$, IL-18, IL-10, IFN- $\gamma$, TNF- $\alpha$ cytokine release by the intestinal tissue in the IEBC was 
determined by applying MilliPlex Porcine cytokine/chemokine magnetic bead panel (PCYTMAG-23 K-08) according to the manufacturer's instructions. Cytokine concentration levels were determined using a BioTek Synergy HT microplate reader (BioTek Instruments Inc., Winooski, VT) at $450 \mathrm{~nm}$ for the ELISA kits or a Luminex $^{\circ} 200^{\text {ma }}$ instrument equipped with the Bio-Plex Manager 6.1 software (Biorad) for the Milliplex assay.

\section{Scanning electron microscope (SEM)}

Scanning electron microscopy (SEM) was used to confirm composition, size and shape of the MNP present in the suspensions used for testing. Samples were prepared for SEM analysis by filtering a fraction of the MNP suspensions over $25 \mathrm{~mm}$ diameter gold coated polycarbonate filters under reduced pressure with pore sizes of $0.8 \mu \mathrm{m}$ and $0.1 \mu \mathrm{m}$ (TJ Environmental). To avoid the agglomeration of the particles, a small amount $(\sim 15 \mu \mathrm{L}$ per sample) of TWEEN-20 (Sigma-Aldrich) was added to the suspensions prior to filtration. After filtration, the filter was transferred onto an aluminum SEM-stub covered with a carbon coated tape. The samples were coated with a thin $(+/-10 \mathrm{~nm})$ conductive surface film of carbon using a carbon evaporator (Quorum Q150 T carbon evaporator) to make the MNP electronically conductive for SEM analyses. The SEM measurements were performed with a Tescan MAIA III GMH field emission scanning electron microscope equipped with a Bruker $\mathrm{X}$-Flash $30 \mathrm{~mm} 2$ silicon drift energy-dispersive X-ray microanalysis detector. The SEM was operated using an acceleration voltage of $15 \mathrm{kV}$. SEM images were recorded using a secondary electron (SE) detector.

\section{Confocal microscopy}

From snap-frozen intestinal tissue segments or MucilAir $^{\mathrm{Tx}}$ inserts cryosections were prepared and fixed with $4 \%$ paraformaldehyde in PBS. Fixed sections were then permeabilized and blocked in 10\% normal goat serum/ $0.2 \%$ Triton X-100/PBS. Sections were incubated with anti-acetylated tubulin IgG2 (1:500) overnight at $4{ }^{\circ} \mathrm{C}$, washed and subsequently incubated with anti-mouse A647 (1:800) and anti-mouse IgG2b A647 (1:800) in combination with anti-phalloidin Alexa568 (1:200) for 2 $\mathrm{h}$ at RT or overnight at $4{ }^{\circ} \mathrm{C}$. Slides were washed 3 times for $15 \mathrm{~min}$ in $\mathrm{PBS}$, one time with MilliQ water and mounted using Vectashield $^{\bullet}$ mounting medium with DAPI. Images were collected with a spinning disk confocal microscopy on an inverted research microscope Nikon Eclipse Ti-E (Nikon), equipped with Plan Apo 10x N.A. 0.45 dry objective (Nikon), Plan Fluor 40x N.A. 1.30 oil objective (Nikon) and Plan Apo VC 100x N.A. 1.40 oil objective (Nikon) and a spinning disk unit (CSU-X1-A1, Yokogawa). The system was also equipped with an ASI motorized stage with the piezo plate MS-
2000-XYZ (ASI), Photometrics Prime BSI sCMOS camera (Teledyne Photometrics) and controlled by the MetaMorph 7.8 software (Molecular Devices). Vortran Stradus $405 \mathrm{~nm}(100 \mathrm{~mW})$, Cobolt Calypso $491 \mathrm{~nm}(100$ $\mathrm{mW})$, Cobolt Jive $561 \mathrm{~nm}(100 \mathrm{~mW})$, Vortran Stradus $642 \mathrm{~nm}(110 \mathrm{~mW})$ lasers were used as the light sources. We used emission filters from ET-BFP2 (49021), ETGFP (49002), ET-mCherry (49008), ET-Cy5 (49006) filter sets mounted into Spinning Disc filter wheel for imaging.

\section{Statistical analysis}

Data are provided as the mean \pm standard deviation or standard error of the mean. Differences between 2 groups were analyzed using 2-tailed Student's t test; 1way ANOVA with Tukey's or Dunnett's post hoc analysis was used for comparisons of multiple groups. Statistical significance was considered at $p<0.05$, and calculations and graphs were generated using GraphPad Prism 8.0 (GraphPad Software Inc.). The supplementary methods can be found in Additional file 1.

\section{Results}

\section{Characterization of the applied microplastic particles}

Scanning electron microscopy (SEM) was used to confirm the composition, size and shape of the diverse set of micro- and nanoplastic particles (MNP) included in the present study (Table 1 and Fig. 1). As particle size descriptor (PSD), the equivalent circular diameter $\left(D_{a}\right)$ was used [27]. For the nylon fibers, the length $(\mathrm{L})$ is given as PSD to provide a more accurate representation of the particle size. Furthermore, the d10, d50 and d 90 of the particle size distribution were calculated, which is the equivalent circle diameter at which 10,50 or $90 \%$ of the number of MNP are smaller. Image analysis of the polystyrene spheres confirmed the expected size for the particles of $0.1,1$ and $10 \mu \mathrm{m}$, but revealed that the particles of $0.05 \mu \mathrm{m}$ were $75 \%$ larger than expected. Fiber length was confirmed for the larger nylon fiber while the length of the smaller fiber was shorter than expected. From the fragmented MNP, the car tire MNP displayed the largest particles, followed by HDPE and the marine MNP from the Ocean Cleanup (OCU). Cleaned HDPE particles showed a lower average fragment size by $19 \%$. Additionally, micro Fourier Transform Infrared microscopy ( $\mu$-FITR) confirmed the polymer makeup of the PS, HDPE and Nylon particles (supplemental Fig. 1).

\section{Effect of MNP on viability and integrity of lung epithelial cells}

We used an advanced 3D in vitro primary cell model representing the human bronchial epithelium, MucilAir ${ }^{\mathrm{ma}}$, to study the effect of MNP exposure via the 
Table 1 Details of the tested MNP. Using SEM, the mean diameter (for spheres and fragments) or length (for fibers) was determined. $n \approx 100$ particles/MNP

\begin{tabular}{|c|c|c|c|c|c|c|c|c|}
\hline \multirow{2}{*}{$\begin{array}{l}\text { Name in } \\
\text { current study }\end{array}$} & \multicolumn{4}{|l|}{ Characteristics } & \multicolumn{4}{|l|}{ SEM data } \\
\hline & Material & Size $(\mu \mathrm{m})$ & Shape & Condition & Mean $D_{a}$ or $L(\mu m)$ & $\mathrm{d} 10(\mu \mathrm{m})$ & $\mathrm{d} 50(\mu \mathrm{m})$ & $\begin{array}{l}d 90 \\
(\mu \mathrm{m})\end{array}$ \\
\hline PS 0.05 & Polystyrene & 0.05 & Sphere & Pristine & 0.09 & 0.07 & 0.08 & 0.14 \\
\hline PS 0.1 & & 0.1 & Sphere & Pristine & 0.10 & 0.09 & 0.10 & 0.11 \\
\hline PS 1 & & 1 & Sphere & Pristine & 1.03 & 1.01 & 1.03 & 1.06 \\
\hline PS 10 & & 10 & Sphere & Pristine & 10.1 & 10.0 & 10.2 & 10.3 \\
\hline PS-F 0.05 & Fluorescent polystyrene & 0.05 & Sphere & Pristine & n.d. & n.d. & n.d. & n.d. \\
\hline PS-F 1 & & 1 & Sphere & Pristine & n.d. & n.d. & n.d. & n.d. \\
\hline PS-F 10 & & 10 & Sphere & Pristine & n.d. & n.d. & n.d. & n.d. \\
\hline HDPE-p & High density polyethylene & $0-80$ & Fragments & Pristine & 40.8 & 21.6 & 32.9 & 71.2 \\
\hline HDPE-c & & $0-80$ & Fragments & Cleaned & 34.2 & 16.9 & 28.6 & 63.9 \\
\hline Nylon $3 \times 13$ & Nylon & $3 \times 13$ & Fiber & Pristine & 10.7 & 10.1 & 10.7 & 11.3 \\
\hline Nylon $10 \times 30$ & & $10 \times 30$ & Fiber & Pristine & 29.5 & 26.4 & 29.4 & 33.1 \\
\hline Nylon spn & Supernatant nylon $10 \times 30$ & n.a. & n.a. & n.a. & n.a. & n.a. & n.a. & n.a. \\
\hline Car tire & Car tire & $0-120$ & Fragments & Cryomilled & 69.1 & 21.7 & 40.1 & 169.5 \\
\hline OCU & Ocean cleanup & $0-40$ & Fragments & Cryomilled & 26.3 & 12.0 & 21.5 & 48.7 \\
\hline
\end{tabular}

$D_{a}$ diameter, $L$ length, n.a. not applicable, n.d. not determined

inhalation route. Exposure occurred through a dropwise distribution of a small volume of MNP suspension at the air-exposed side of the lung cells and effects on cell viability and integrity were subsequently assessed. The amount of lactate dehydrogenase (LDH) released by cells or tissue is a commonly used marker to assess viability as upon damage the amount of released LDH increases $[25,28,29]$. We used the detergent Triton X-100 to induce the maximum LDH release by the lung cells and compared all other conditions to it (Fig. 2A). After $24 \mathrm{~h}$, LDH release was $0.62 \pm 0.13 \%$ under control conditions which increased up to $4.3 \pm 2.0 \%$ and $8.4 \pm 4.0 \%$ after 48 and $96 \mathrm{~h}$, respectively. None of the MNP evoked a loss of cell viability as comparable LDH levels were observed between control and MNP-exposed conditions at all timepoints. Integrity of the lung cell model was assessed by measuring the transepithelial electrical resistance (TEER) before $(\mathrm{t}=0)$ and after 24,48 and $96 \mathrm{~h}$ of exposure (Fig. 2B). As demonstrated before and potentially due to physical challenge [30], in the first $24-48 \mathrm{~h}$ after exposure TEER increased under control conditions (Fig. $2 \mathrm{~B}$, inset). In line with the maximally released LDH for Triton X-100 damaged lung cells, TEER strongly decreased within $24 \mathrm{~h}$ upon exposure to Triton X-100, indicating maximum destruction of the lung cell barrier integrity. A significant lower relative TEER compared to the control condition was noted for nylon $3 \times 13$ (56.1 \pm 8.6\%). Furthermore, after $48 \mathrm{~h}$ exposure to larger $(10 \times$ 30) nylon fibers or the supernatant of these fibers, a non-significant trend of decreased relative TEER (45.6 \pm $27.8 \%$ or $39.2 \pm 1.4 \%$, respectively) was observed. HDPE- c showed a significant decreased barrier integrity after $48 \mathrm{~h}$ of exposure only, hinting towards a slower onset of effects for this MNP. None of the other MNP significantly affected the barrier integrity, but PS 10 and car tire showed clear trends to lower the relative TEER with $\sim 20 \%$ after $24 \mathrm{~h}(80.2 \pm 17.7 \%$ or $80.9 \pm 20.3 \%$, respectively), which were sustained and increased after $48 \mathrm{~h}$ of exposure with a further decrease in TEER of $~ 30 \%$ for both MNP (PS $1050.1 \pm 27.6 \%$, car tire $50.6 \pm 13.3 \%$ ). After $96 \mathrm{~h}$ of exposure, TEER was no longer decreased in the conditions with PS particles, HDPE-c or nylon supernatant, but (non-significant) trend effects were still noted for nylon $10 \times 30$ fibers and now for the first time also for $\mathrm{OCU}$, indicating once again the possibility for a slower onset of effects upon exposure to these specific MNP.

\section{Viability and effects on intestinal permeability of MNP exposed to human and porcine ex vivo intestinal tissue explants}

By using intestinal tissue explants of human and porcine origin we recapitulated the in vivo complexity in architecture and morphology of the gastrointestinal epithelial barrier in an ex vivo setting. Based on the MucilAir ${ }^{\text {Tx }}$ results, six MNP were selected for exposure to human colon intestinal tissue using the InTESTine ${ }^{\mathrm{Tm}}$ in vitro model [24, 25]. Although no positive control could be included in the current experiment due to the limited availability of fresh tissue, multiple historic InTESTine ${ }^{\mathrm{m}}$ studies using $0.1 \%$ Triton X-100 as positive control show similar (negative) effects on intestinal permeability and 

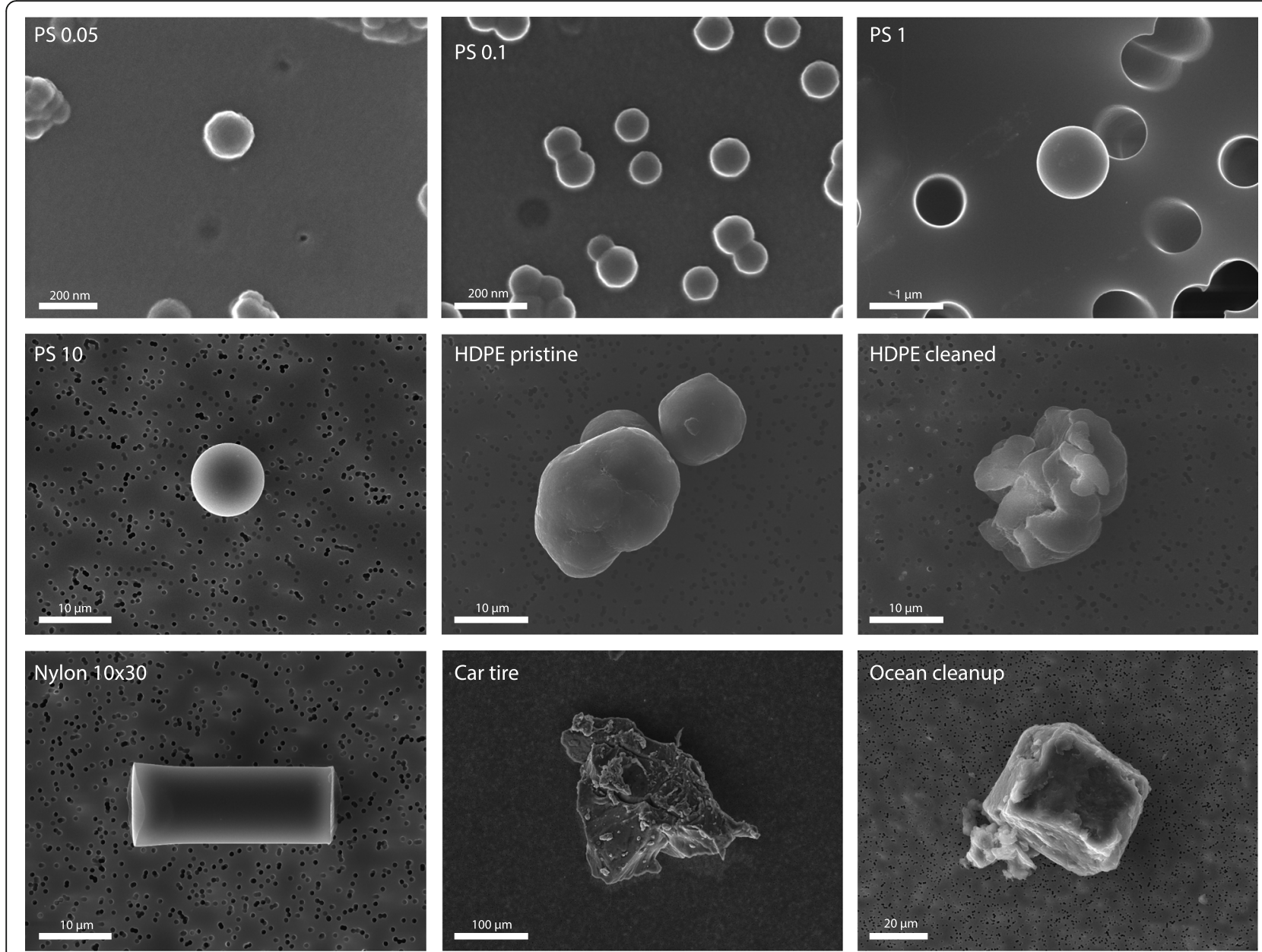

Fig. 1 Characterization of micro- and nanoplastic particles by scanning electron microscopy (SEM). Representative images of polystyrene (PS) spheres of $0.05,0.1,1$ and $10 \mu \mathrm{m}$, high density polyethylene (HDPE) fragments, the nylon fiber of $10 \times 30 \mu \mathrm{m}$, car tire and ocean cleanup fragments

tissue viability (supplemental Fig. 2A-C). Upon $4 \mathrm{~h}$ exposure, viability of the human colon tissue explants was not affected as the release of LDH was similar for control and MNP exposed conditions (Fig. 3A). To study intestinal functionality, we analyzed the transport of two small molecule model drugs: mannitol, a low permeable drug that translocates via the paracellular route, and caffeine, a high permeable drug that translocates via the paracellular route [31]. Based on our previous human colon InTESTine ${ }^{\text {tw }}$ results we applied a cutoff value of 2 for the caffeine/mannitol transport ratio to define proper tissue functionality [25]. Under control conditions, mannitol transport was low with an apparent permeability $\left(\mathrm{P}_{\text {app }}\right)$ of $5.1 \pm 1.4 \times 10^{-6} \mathrm{~cm} / \mathrm{s}$ or $6.5 \pm$ $0.8 \times 10^{-6} \mathrm{~cm} / \mathrm{s}$ between 1 and $2 \mathrm{~h}$ and $2-4 \mathrm{~h}$, respectively, while caffeine transport was at least 2 -fold higher with $\mathrm{P}_{\mathrm{app}}$ values of $14.2 \pm 6.3 \times 10^{-6} \mathrm{~cm} / \mathrm{s}$ and $14.4 \pm 3.0 \times 10^{-6} \mathrm{~cm} / \mathrm{s}$ between 1 and $2 \mathrm{~h}$ and $2-4 \mathrm{~h}$, respectively (Fig. 3B and supplemental Fig. 2D-E).
Exposure to polystyrene particles of 1 and $10 \mu \mathrm{m}$ or pristine HDPE fragments significantly decreased the caffeine/mannitol $\mathrm{P}_{\text {app }}$ ratio between 1 and $2 \mathrm{~h}$. Although the caffeine/mannitol $\mathrm{P}_{\text {app }}$ ratio remained above 2 for both PS conditions, the criterion for proper tissue functionality could not be met for pristine HDPE $\left(1.9 \pm 0.03 \times 10^{-6} \mathrm{~cm} / \mathrm{s}\right)$. Between 2 and $4 \mathrm{~h}$ of incubation, caffeine/mannitol $\mathrm{P}_{\text {app }}$ ratios further decreased and dropped below the criterion of 2 for all three MNP. Exposure of the human colon tissue explants to OCU and car tire fragments also decreased tissue functionality between 2 and $4 \mathrm{~h}$. For polystyrene particles of $0.05 \mu \mathrm{m}$, caffeine/mannitol $\mathrm{P}_{\text {app }}$ ratios were lower than the control condition at all timepoints but remained above 2 for the length of the experiment (not significant). For most MNP the decreased caffeine/mannitol $\mathrm{P}_{\text {app }}$ ratios were a result of reduced caffeine transport with the exception of $\mathrm{OCU}$, for which caffeine transport remained intact 


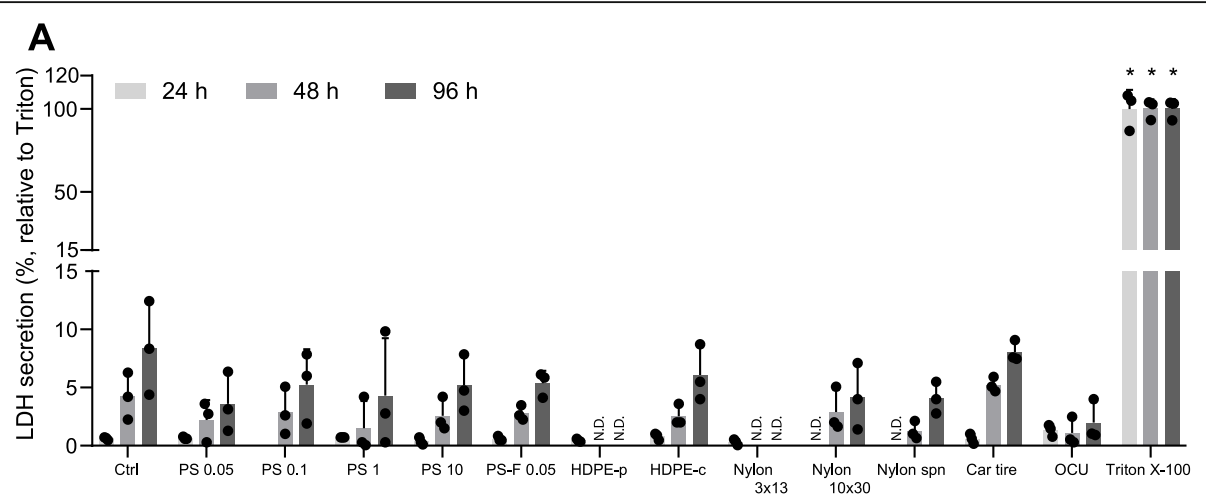

B

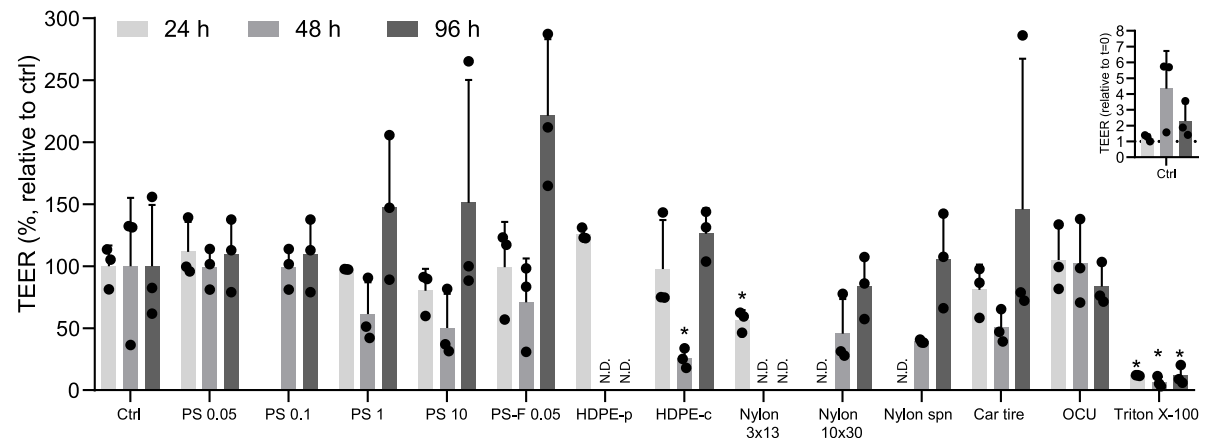

Fig. 2 Viability and integrity measurements in the lung epithelial cell model MucilAir ${ }^{T M}$ upon 24, 48, and $96 \mathrm{~h}$ exposure to MNP (1 mg/mL). A The release of lactate dehydrogenase $(\mathrm{LDH})$ into the basolateral compartment was measured as a marker of cell viability. Maximum LDH release was achieved by exposure to Triton X-100 0.1\%, and all other values were expressed as percentage relative to the maximum release. B Transepithelial electrical resistance (TEER) as marker for barrier integrity was measured before ( $\mathrm{t}=0 \mathrm{~h}$ ) and after exposure. Per condition, TEER at $\mathrm{t}=0 \mathrm{~h}$ was normalized to 1 and subsequent measurements were expressed relative to $\mathrm{t}=0 \mathrm{~h}$. Additionally, at every timepoint, ctrl TEER was set at 100\%, and all other values were expressed as percentage relative to the ctrl. Inset: relative TEER under control conditions over time. TEER at $\mathrm{t}=0 \mathrm{~h}$ was normalized to 1 (dotted line) and subsequent measurements were expressed relative to $\mathrm{t}=0 \mathrm{~h}$. Data are presented as mean $\pm \mathrm{SD}$. ${ }^{*} p<0.05$ compared to the control condition, calculated by one-way ANOVA (Dunnett's multiple comparisons). N.D. = not determined

and mannitol transport increased slightly compared to the control condition (supplemental Fig. 2D-E).

Anatomically, but also at transporter and enzyme protein level, the gastrointestinal (GI) tract of the omnivorous pig is highly similar to the human GI tract $[32,33]$. Furthermore, it was demonstrated that porcine intestinal tissue is a good alternative to predict intestinal permeability in humans with the advantage of being more widely available and having the possibility to study multiple intestinal regions, aspects rather limited for human intestinal tissue [24]. Here, we applied porcine jejunum, ileum and colon tissue in the InTESTine ${ }^{\mathrm{Tu}}$ model to study regional effects of MNP. Based on the results obtained with human colon tissue we exposed the porcine intestinal tissue to (fluorescent) polystyrene particles of different sizes for $5 \mathrm{~h}$. Under control conditions, LDH secretion was the highest in jejunum, followed by ileum and subsequently colon (Fig. 3C). With $5.6 \pm 0.7 \%$, LDH release under control conditions in porcine colon after $5 \mathrm{~h}$ was comparable to the release by human colon tissue after $4 \mathrm{~h}$ (Fig. 3A, $5.0 \pm 0.4 \%$ ), showing the robustness of the model and comparability between human and porcine intestinal tissue. All polystyrene particles significantly increased the LDH release in ileum and colon tissue and the three fluorescent polystyrene particles also significantly increased the LDH release in jejunum intestinal tissue, hence indicating that these MNP at the applied concentrations affected tissue viability in the current setup. The relatively short timeframes of 4 and $5 \mathrm{~h}$ that we applied here were inherent to the limited lifespan of using ex vivo intestinal tissue explants in static in vitro models such as the InTESTine ${ }^{\mathrm{Tm}}$ or the Ussing chamber and this is one of the main limitations in such studies [34-37]. Applying microfluidics to so-called intestineon-a-chip models, thereby providing relevant microenvironmental context such as mechanical shear stress [38], has shown to sustain ex vivo tissue viability for $\geq 24 \mathrm{~h}[39,40]$. Using our recently developed Intestinal Explant Barrier Chip (IEBC) [26] we exposed porcine colon tissue for $24 \mathrm{~h}$ to MNP. Under control conditions LDH release was $23.1 \pm 3.6 \%$ in the IEBC (Fig. 3D), in 

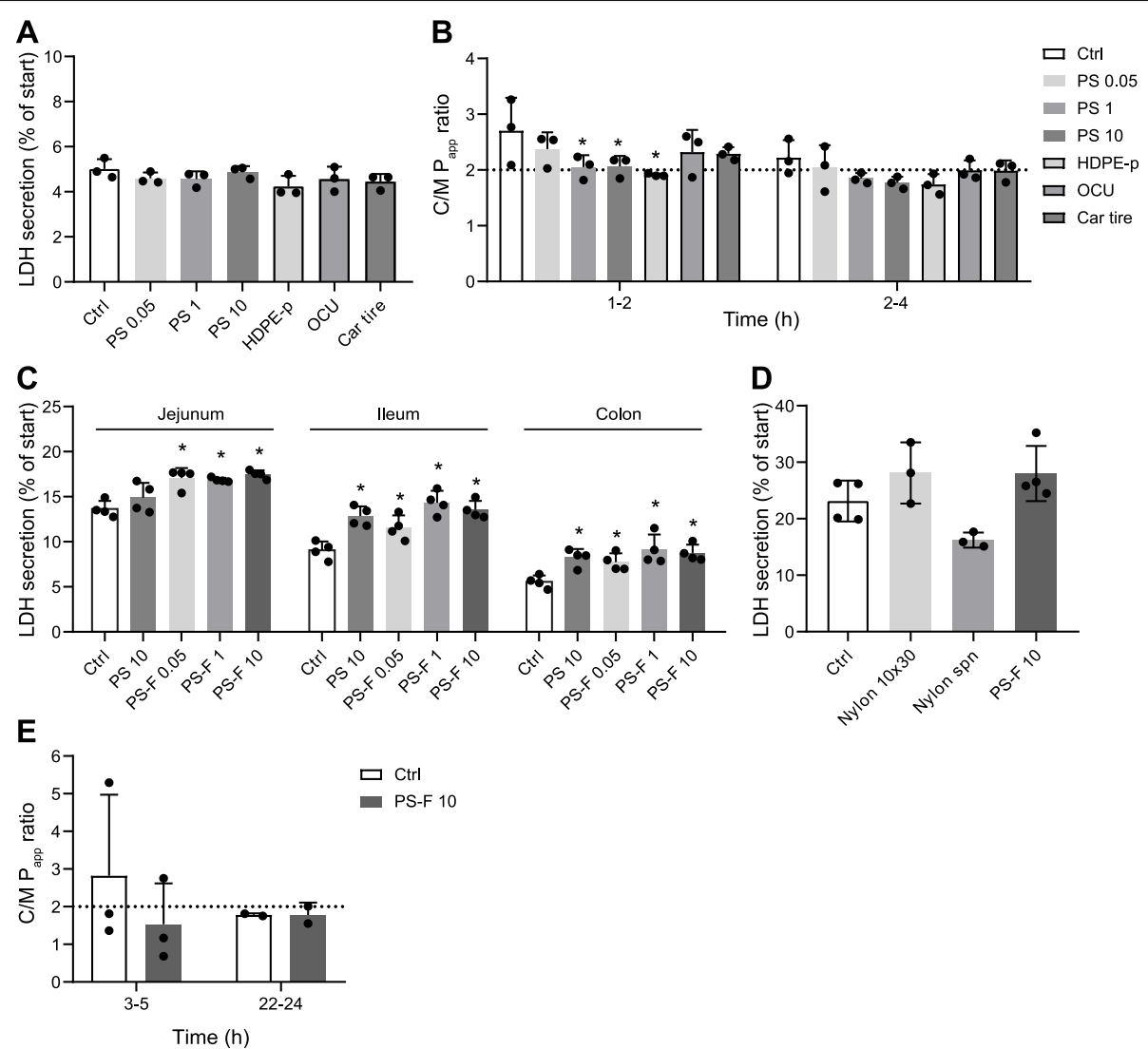

Fig. 3 Viability and functionality of human and porcine intestinal tissue explants upon exposure to MNP (1 mg/mL). A-B Human colon tissue explants were mounted in the InTESTine ${ }^{T M}$ and exposed to MNP for $4 \mathrm{~h}(n=3)$. A Cumulative LDH release into the apical and basolateral compartment. B Ratio of caffeine/mannitol (both applied at $10 \mu \mathrm{M}$ ) apparent permeability $\left(\mathrm{P}_{\text {app }}\right)$, calculated between 1 and 2 and $2-4 \mathrm{~h}$ of incubation. Cutoff for proper tissue functionality is 2, indicated by the dotted line. C Cumulative LDH release into the apical and basolateral compartment of porcine jejunum, ileum and colon tissue explants mounted in the InTESTine ${ }^{\text {TM }}$ and exposed to MNP for $5 \mathrm{~h}(n=4)$. D-E Control and PS-F 10 exposed porcine colon tissue explants in the Intestinal Explant Barrier Chip (IEBC) for $24 \mathrm{~h}(\mathrm{n}=3-4)$. D Cumulative LDH release into the apical and basolateral compartment. E Ratio of caffeine/mannitol (both applied at $10 \mu \mathrm{M}$ ) $\mathrm{P}_{\text {app }}$ calculated between 3 and 5 and $22-24 \mathrm{~h}$ of incubation. Cutoff for proper tissue functionality is 2, indicated by the dotted line. Data are presented as mean \pm SD. ${ }^{*} p<0.05$ compared to the control condition, calculated by one-way ANOVA (Dunnett's multiple comparisons)

line with the InTESTine ${ }^{\text {Tn }}$ results (Fig. 3C, $5.6 \pm 0.7 \%$ after $5 \mathrm{~h}$ ). The LDH release tends to increase upon exposure to the fluorescent polystyrene particles of $10 \mu \mathrm{m}$ and the nylon fibers (not significant), but not when exposed to its supernatant. Control and PS-F 10 conditions were co-incubated with caffeine and mannitol to assess the effect on tissue functionality. Between 3 and $5 \mathrm{~h}$, tissue functionality was good under control conditions, as indicated by a caffeine/mannitol $\mathrm{P}_{\text {app }}$ ratio above 2, but not for the tissue exposed to PS-F 10 (Fig. $3 \mathrm{E}$ and supplemental Fig. 2E-F; caffeine/mannitol $\mathrm{P}_{\text {app }}$ ratio of $1.5 \pm 1.1$ ). These results are in agreement with the InTESTine ${ }^{\mathrm{Tx}}$ data obtained for the non-fluorescent PS $10 \mathrm{MNP}$ in human colon tissue between 1 and $4 \mathrm{~h}$. With a caffeine/mannitol $\mathrm{P}_{\text {app }}$ ratio of $1.8 \pm 0.04$ or $1.8 \pm 0.3$ under control or PS-F 10 conditions, respectively, tissue functionality was comparable in both conditions between 22 and $24 \mathrm{~h}$.

\section{Nylon (supernatant) evokes pro-inflammatory cell activation}

When MNP (or chemicals leaching from the particles) come in contact with cells, this may lead to local effects on the immune system [41]. Here we included nylon supernatant as an example of exposure to environmental leaching of MNP-associated chemicals. As the response of the immune system takes days rather than hours, we evaluated the release of pro-inflammatory cytokines after $96 \mathrm{~h}$ in the MucilAir ${ }^{\mathrm{mu}}$ human lung cell model or after $24 \mathrm{~h}$ in the IEBC with porcine colon tissue. A mixture of TNF- $\alpha$, LPS and fetal calf serum, hereafter called cytomix, was included as positive control to induce a proinflammatory immune response. Lung cell secretion of IL-6 was significantly increased upon exposure to cytomix (Fig. 4A). From the MNP, nylon supernatant induced the highest IL-6 release (6-fold increase compared to control), followed by PS 10 (4-fold), car tire (2.5-fold) 

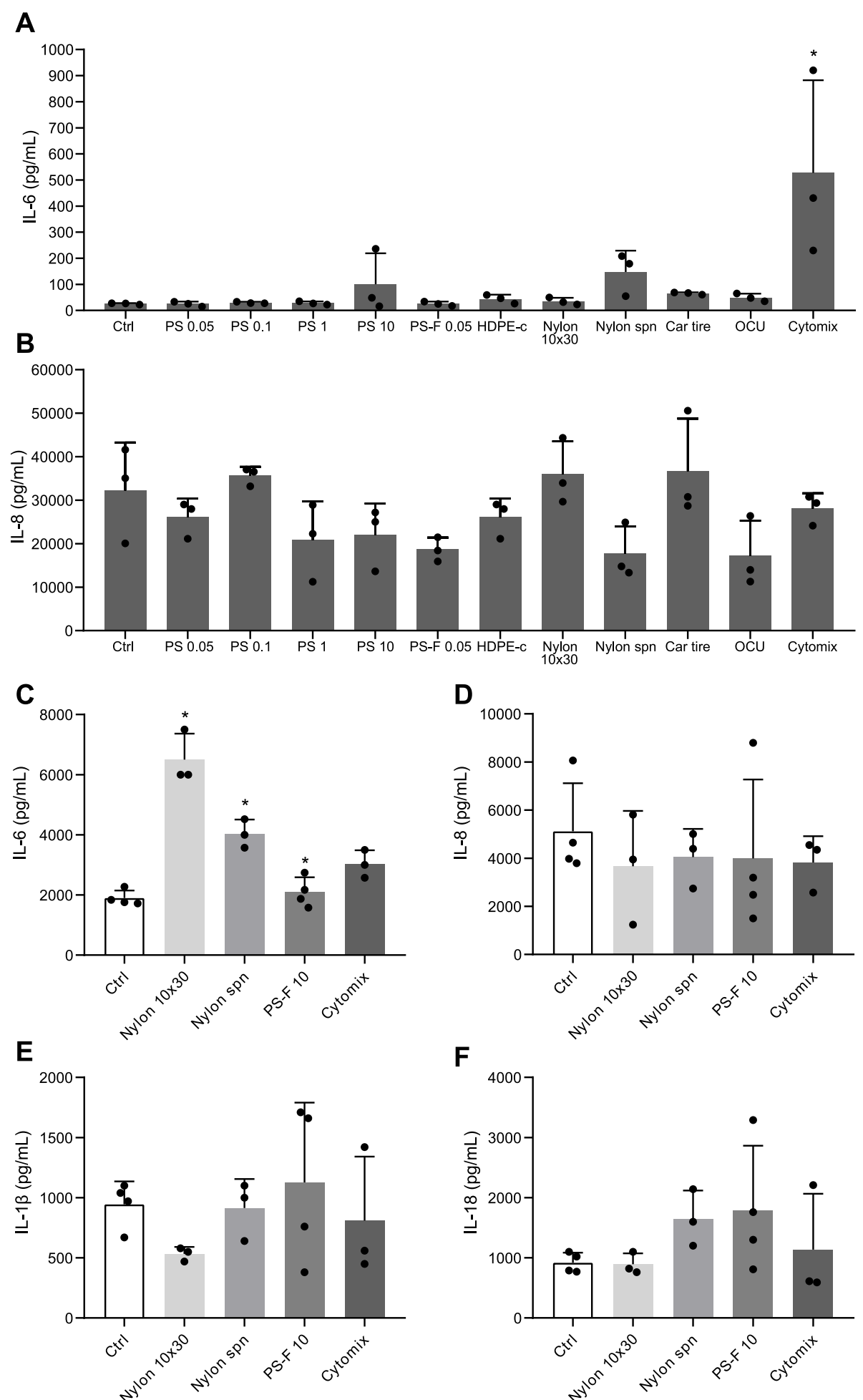

Fig. 4 Pro-inflammatory cytokine release by lung epithelial cells or porcine colon intestinal tissue explants upon 96 or $24 \mathrm{~h}$ exposure, respectively, to MNP (1 mg/mL). A-B IL-6 (A) and IL-8 (B) secretion into the basolateral compartment by lung epithelial cells (MucilAir $\left.{ }^{\mathrm{TM}}\right)$ after $96 \mathrm{~h}(\mathrm{n}=3)$. C-F IL-6 (C), IL-8 (D), IL-1 $\beta(\mathbf{E})$ and IL-18 (F) secretion into the basolateral compartment by porcine colon tissue explants mounted in the IEBC after 24 $h(n=3-4)$. Data are presented as mean \pm SD. ${ }^{*} p<0.05$ compared to the control condition, calculated by one-way ANOVA (Dunnett's multiple comparisons) 
and OCU (2-fold). None of the MNP, but also not cytomix, increased the secretion of IL- 8 by the lung cells (Fig. 4B). In addition to IL-6 and IL-8, we assessed 5 additional cytokines in the IEBC experiment. No results were obtained for IFN- $\gamma$, TNF- $\alpha$ and IL-10 as concentrations were below the limit of detection (except for TNF$\alpha$ in the cytomix positive control condition). Cytomix significantly increased the secretion of IL-6, as did the nylon fibers and its supernatant (Fig. 4C). In line with the results of the lung cell model, nor cytomix nor any of the MNP affected the release of IL-8 (Fig. 4D). Exposure to PS-F 10 resulted in a high IL-1 $\beta$ release by 2 of the 4 colon tissue segments and both PS-F 10 and nylon supernatant provoked a 2 -fold increase in IL-18 secretion (Fig. 4E-F). The combined results of the advanced lung and intestinal models show that nylon $10 \times 30$ fibers and its supernatant, and possibly also (fluorescent) polystyrene particles of $10 \mu \mathrm{m}$, have immunogenic potential with predominantly effects on the local secretion of the pro-inflammatory cytokine IL-6.

\section{Fluorescent polystyrene MNP cross the lung and intestinal epithelial barrier}

In addition to the potential adverse biochemical and biological responses of MNP-exposed lung and intestinal epithelial cells, it is of interest to assess particle uptake and accumulation. Therefore, we applied fluorescently labeled polystyrene particles of different sizes and determined apical to basolateral permeability and epithelial penetration by plate reader measurements and confocal microscopy, respectively. After $24 \mathrm{~h}$, permeability of PSF 0.05 in the MucilAir ${ }^{\mathrm{rm}}$ lung cell model reached $3.6 \pm$ $1.2 \%$ (Fig. 5A). In a second experiment applying the same MNP, a comparable permeability was shown between 0 and $48 \mathrm{~h}$ (first dose) and 48-96h (2nd dose) of approximately 6-9\%. Confocal microscopy confirmed the penetration of PS-F 0.05 into the MucilAir $^{\text {tix }}$ lung epithelium by showing green fluorescence in the PS-F 0.05-exposed cell system only, and not in the blanc control (Fig. 5B). As both big and small green fluorescent structures were visible, it is possible that the $0.05 \mu \mathrm{m}$ size microparticle beads aggregate (upon intracellular absorption) to form larger clusters.

Using porcine jejunum, ileum and colon tissue, regional differences in intestinal permeability were assessed. Furthermore, particles of $0.05,1$ and $10 \mu \mathrm{m}$ were used to determine if particle size influenced uptake. Between regions, no significant differences were observed in particle uptake after $5 \mathrm{~h}$ exposure (Fig. 5C). The highest permeability was observed for PS-F 10 with an average uptake of $3.37 \pm 0.46 \%$ along the 3 intestinal regions. For PS-F 0.05 and PS-F 1, permeability was much lower with an average uptake of $0.30 \pm 0.01 \%$ or $0.62 \pm 0.03 \%$, respectively. Presence of fluorescent particles in the basolateral medium was confirmed by fluorescent microscopy (Supplemental Fig. 3A-B). As PS-F 10 showed the highest permeability after $5 \mathrm{~h}$ of exposure, we choose this MNP to determine the $24 \mathrm{~h}$ uptake using porcine colon tissue in the IEBC. With $1.6 \pm$ $0.1 \%$ after $5 \mathrm{~h}$ exposure, PS-F 10 uptake was lower under microfluidic conditions in the IEBC than under static conditions in the InTESTine ${ }^{\mathrm{Tm}}$ (Fig. 5D). After $24 \mathrm{~h}$, a total amount of $5.5 \pm 1.3 \%$ was translocated to the basolateral side of the colon tissue segment. As for the lung model, confocal microscopy confirmed the presence of the fluorescent MNP in the intestinal tissue segments (Fig. 5E-G and supplemental Fig. 4A-C). A clear intestinal tissue structure was observed with the lining of the muscularis mucosa and crypt and/or villi structures marking the basolateral and apical side, respectively, of the tissue segment. The fluorescent polystyrene particles are visualized as round spheres in all 3 intestinal regions (Fig. 5E and supplemental Fig. 4A). Most particles were observed at the apical, and thus exposed, side, but particles have also penetrated deeper into the tissue segments. Interestingly, the absorbed particles seemed to cluster together at several locations in the tissue segments. At higher magnifications it is clear that especially for PS-F 1 these clusters can contain more than 50 single entities (Fig. 5F and supplemental Fig. 4B). To investigate where the MNP are situated, e.g. on top or below the cells or in the same plain, orthogonal representations were made of PS-F 1 and PS-F 10 inside jejunum tissue (Fig. 5G). These images show that the particles were located in the same Z-stack position as the cells meaning that the particles are next or even inside the cells, and not on top or below the cells. This assumption is supported by close-ups of the acetylated-tubulin and phalloidin staining of the cytoskeleton showing that the PS-F 10 particles are situated inside the cell structure as the cytoskeleton has formed itself around the MNP (Supplemental Fig. 4C). To verify whether MNP truly access (the intestinal) cells should be investigated in future research as the current set of images cannot provide this answer. Nevertheless, these results strongly suggest that particle uptake (with a size $\leq 10 \mu \mathrm{m}$ ) is of relevant concern upon MNP inhalation or ingestion.

\section{Discussion}

An increasing number of in vitro studies suggest that MNP are taken up and affecting epithelial cells (A549, BEAS-2B, Caco-2) in a material and size-dependent way, but studies using more advanced physiologically relevant 3D barrier models are rare. To the best of our knowledge, this is the first study revealing the passage of the same set of MNP over the epithelium of advanced in vitro models for both the lung and intestine barrier. Furthermore, pro-inflammatory cell activation and 


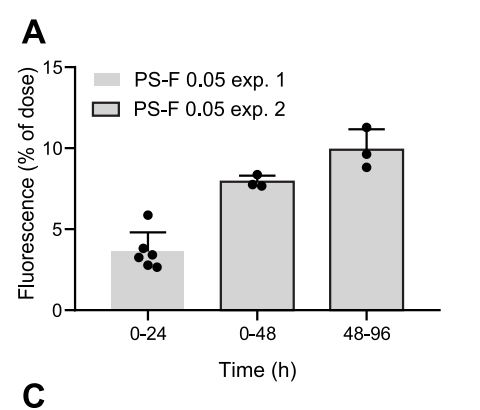

B
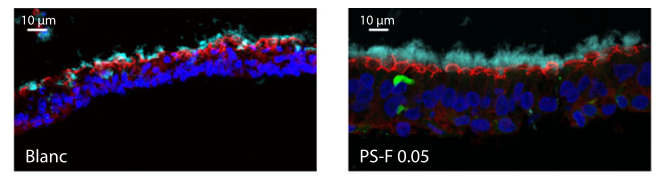

C

D
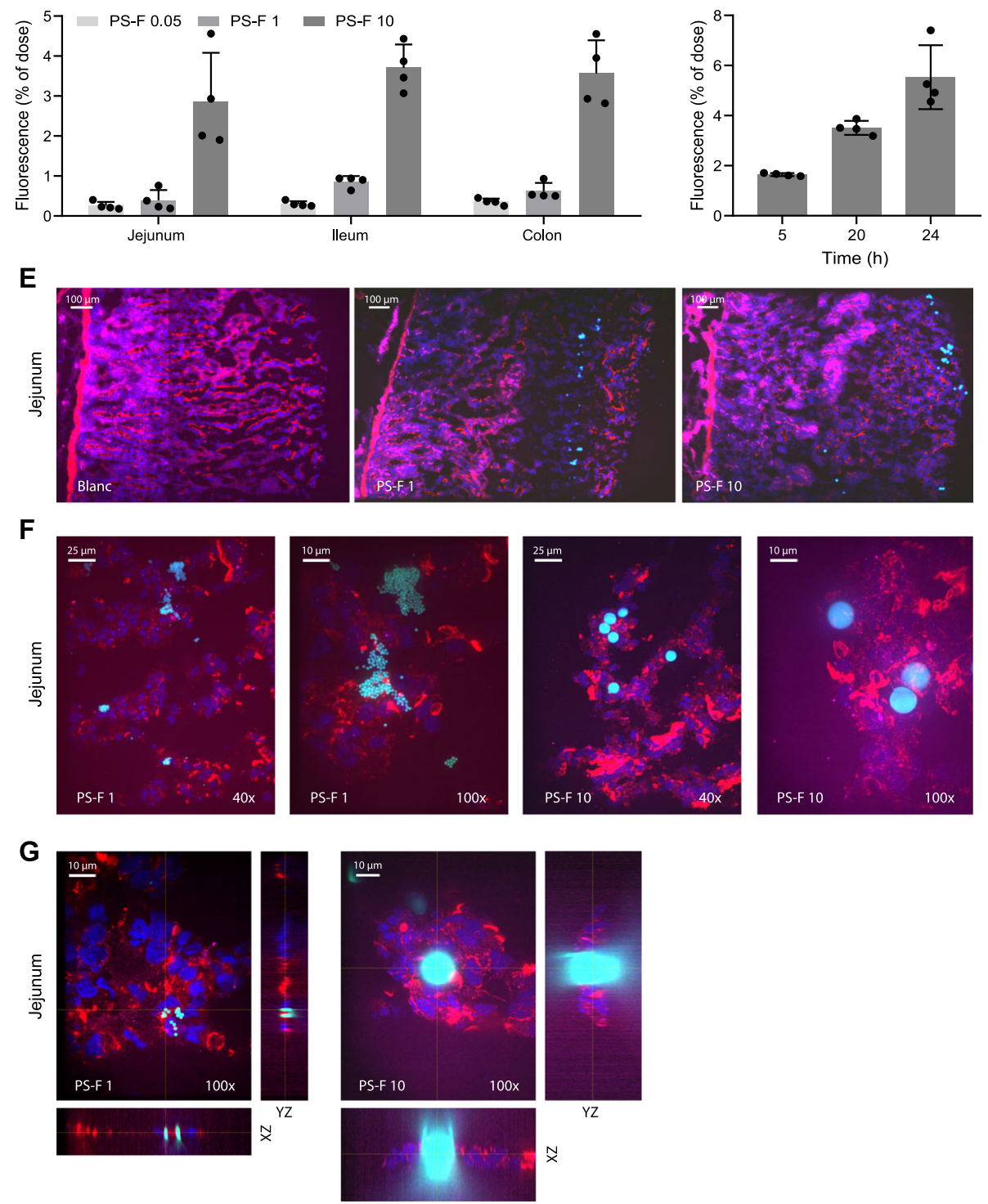

Fig. 5 (See legend on next page.) 


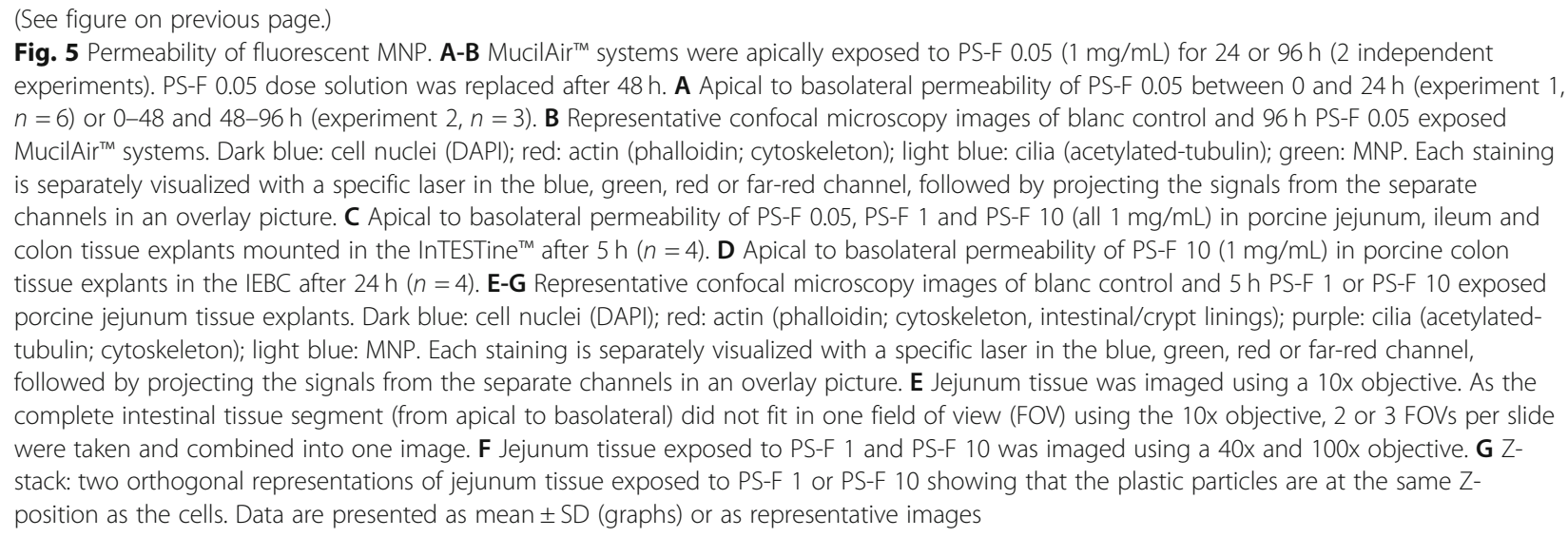

disrupted barrier integrity were observed after exposure to several of the tested MNP. With intact 3D tissue architecture, cell type diversity and physiological characteristics such as mucus production, the MucilAir ${ }^{\mathrm{max}}$, InTESTine $^{\text {ts }}$, and IEBC models offer more in vivo-like complexity than the majority of conventional lung and gut in vitro models that are based on monolayers of cell lines. Especially the aspect of full tissue thickness in our advanced models adds value in comparison to the sensitive single layer cellular models when assessing not only epithelial barrier disturbances but also the lumen-toblood permeation of compounds in vitro.

With increasing evidence gathered over the past decade indicating the presence of MNP inside the animal and human body, intake of MNP and their associated chemicals via diet and inhalation shifted from threat to real phenomenon. Honey, beer, bottled but also tap water, salt and seafood have been identified as potential food sources for human consumption of MNP [16, 4245]. Among the discovered MNP in foods are PET, PS and PE particles [42] with fibers being the most commonly consumed type of particle, followed by fragments [43]. The detection of MNP in atmospheric fallout [46] points towards the omnipresence of airborne MNP for which textile, e.g. nylon, and flock (microfibre) industry have been identified as important sources, but also car tires and degradation of agricultural plastics and fertilizer have been described [47-49]. By using PS, HDPE, nylon, car tire and OCU fragments, we have tried to recapitulate the diversity of MNP types and shapes that have been found as air- or foodborne contaminators. Furthermore, we included the so-called nylon supernatant as example of exposure to environmental leakage of MNP-associated chemicals. The size of the MNP used in the current study lies within the range typically found for environmental MNP $[16,42]$ and the size heterogeneity of such environmental samples of MNP is mimicked with our HDPE, car tire and OCU particles. The use of fluorescently labeled PS of different sizes allowed us to study size-dependent effects in particle uptake, as it was described previously that permeability can highly vary between differently sized particles influenced by the various possibilities that cells and cell layers have to facilitate uptake $[16,20,50,51]$. Only limited knowledge exists about daily human exposure to MNP and with estimates of $\sim 50$ particles consumed/day [43] or $40 \mathrm{mg}$ ingested inorganic microparticles/day [52] the exact particle concentration to which the lung or intestinal epithelium are exposed is guesswork. The applied concentration of $1 \mathrm{mg} / \mathrm{mL}$, reflecting a dose of $150 \mu \mathrm{g} / \mathrm{cm}^{2}$ (MucilAir $\left.{ }^{\mathrm{Tm}}\right)$ or $\sim 500 \mu \mathrm{g} / \mathrm{cm}^{2}\left(\right.$ InTESTine $\left.^{\mathrm{Tm}}\right)$, in the current study likely exceeds daily exposure, but was chosen in line with dose administrations in other in vitro and in vivo studies [53-57]. Furthermore, it is expected that hazardous effects and differences between MNP are identified with less effort when using a relatively high concentration, administered here as an acute single dose. Administration occurred as liquid suspension in all our experiments, which might sound counterintuitive for the lung epithelial model having an airliquid interface and can therefore also be exposed to aerosols. We however choose to apply the MNP in a minimal droplet based on the following: 1) We showed similar results for droplet and air exposure for $\mathrm{CeO}_{2}$ and $\mathrm{CuO}$ particles based on gene expression as a readout parameter (unpublished results), 2) air exposure would require high amounts of MNP, which are not available for the selected subset of microplastics. Based on these compiled results we believe that droplet exposure to lung epithelial model as applied in this study mimics exposure of MNP via inhalation.

For uptake, particles $<2.5 \mu \mathrm{m}$ and fibers are of most concern for the lungs whereas also larger particles can be taken up by the intestinal tissue [16], and our particles to study uptake were selected accordingly. MNP uptake was quantified with transport rates of approximately $3.5 \% \quad(0.05 \mu \mathrm{m}$-sized $\quad$ PS-F $)$ or $5.5 \%$ $(10 \mu \mathrm{m}$-sized PS-F) per $24 \mathrm{~h}$ across our models of the 
lung or intestinal epithelial barrier, respectively. Furthermore, we demonstrated that the intestinal absorption of large PS particles $(10 \mu \mathrm{m})$ was higher than that of smaller PS particles $(0.05-1 \mu \mathrm{m})$. In contrast to previous in vitro studies using cellular monolayers, MNP uptake in the present study not just means that the epithelial cells might have the capability to internalize or absorb particles, but also emphasize that these particles can translocate all the way through multiple cell layers into the basolateral compartment. Previous research into lung or intestinal MNP uptake has been conducted mostly in the A549 or Caco-2 cells lines, which are the most frequently applied cell lines in lung or intestinal research, respectively $[20,50,51,53,58]$. Using mostly fluorescently labeled PS particles, MNP uptake has been demonstrated in A549 cells for different particles with a size smaller than $100 \mathrm{~nm}[50,51]$, and in Caco-2 cells for particles with a size ranging from $0.1-10 \mu \mathrm{m}[20,58]$. Although these studies assessed the amount of MNP located inside or on top of the cells, no quantitative results were obtained for penetration through the epithelial cell layer into the basolateral medium. In line with our results that show a higher uptake for larger particles by the intestinal epithelium, Caco-2 cells showed more internalization of $4 \mu \mathrm{m}$ sized particles than $1 \mu \mathrm{m}$ particles [20]. Interestingly, higher particle uptake was noted for Caco-2 co-cultures with either HT29-MTX cells or Raji B cells compared to Caco-2 alone [20], suggesting that the use of more complex models increase the predictive value for the in vivo situation. Unlike our findings, $10 \mu \mathrm{m}$ sized particles were hardly taken up by Caco-2 cells [20]. One of the possible explanations for this discrepancy can be that a simplistic model with just the epithelial cells omits other cell types present in the epithelial layer that might play a more prominent role in the endocytosis of larger MNP. For example, as reviewed by Wright and Kelly 2017 in the gastrointestinal tract the Peyer's patches of the ileum play an important role in the uptake and translocation of particles in the range of $0.1<10 \mu \mathrm{m}$ via endocytosis [16]. Another explanation for the lack of uptake of $10 \mu \mathrm{m}$ sized particles by Caco- 2 cells can be the much tighter barrier integrity, as measured by TEER, for Caco-2 cells in comparison to intestinal tissue explants [30], thereby likely underestimating the fraction of MNP that are able to pass the intestinal barrier in vivo. For A549 cells the opposite is the case, as it has a poor barrier integrity due to the lack of functional tight junctions, thereby easily overestimating compound permeability $[59,60]$. Again it was demonstrated that particle size influenced uptake as one study showed that uptake by A549 cells was higher for $40 \mathrm{~nm}$ particles compared to 20 or $100 \mathrm{~nm}$ sized particles [51]. Although it has been demonstrated that translocation efficiency increased when particle size decreases [61, 62], it is also known that different uptake mechanisms are at play for different size fractions. Besides endocytosis, the phenomenon of persorption is another route of uptake covering particles even up to $130 \mu \mathrm{m}$ via mechanical kneading through gaps in the intestinal epithelium at the villus tips [16]. A major limitation of (almost) all in vitro and in vivo studies, including the study presented here, towards particle uptake is that so far only spherical shaped polystyrene particles are used. The reason for this is the availability of these spheres with a fluorescent label, simplifying the detection. As environmental MNP are more often not spherical and more fragmentized, extrapolation of experimental particle uptake data to assess human risk exposure should be done with care and will benefit from evaluating uptake of particles with a broader diversity in not only shape, but also material composition. A broader availability of fluorescently, or otherwise, labeled particles would obviously ameliorate such studies.

From all the tested MNP, car tire, PS of $10 \mu \mathrm{m}$, nylon fibers and the nylon supernatant stand out as the particles evoking adverse effects on the barrier integrity and proinflammatory cell activation in our lung and intestinal models. The finding that in addition to the particles themselves, also the nylon supernatant could elicit cytotoxic effects emphasize that leaching chemicals or other particleassociated factors should also be considered as being destructive. In fact, a recent study focusing on the effect of polyester and nylon microfibers, the same nylon microfibers used in this study, in human and murine alveolar and airway organoids attributed the negative effects on cell growth and development of nylon specifically to its leaching chemicals [63]. The negative effects reported in the current study for nylon fibers might therefore potentially also being caused by leaching chemicals and not, or to a lesser extent, by the particle itself. However, which components in the nylon supernatant caused the negative effects in the airway model of van Dijk et al. and in our advanced in vitro models of the lung and intestinal epithelial barrier could not be identified so far [63]. Chemical leaching might also play a role for the car tire particles as different additives are used in car tire manufacturing and toxic components have been found to leach from tire rubber $[64,65]$. Likewise, detrimental leachate effects on sea urchin embryo development have been shown previously for the same HDPE fluff stock as that we used in our study and for PS particles, but the latter were from a different source [66]. For HDPE six aliphatic hydrocarbons (C14, $\mathrm{C} 16, \mathrm{C} 18, \mathrm{C} 20$, and $\mathrm{C} 22$ ) were detected in the leaching solutions [67] and they might have caused the negative effects on the sea urchin embryos. In an attempt to avoid HDPE leaching effects in the current study, we also included hexane-cleaned HDPE (HDPE-c). For the applied PS particles in this study we have no information on 
possible chemical leachates, but the supplier information shows that the PS particles are almost purely composed of polystyrene (97.5\%) and polystyrene divinylbenzene (2.5\%), although they might contain possible residual proprietary surfactants [68]. For all other MNP used in this study we have no technical specifications from the supplier on the use of additives. Previous reports on cytotoxicity and immune-modulating effects of MNP vary widely within and between cell types, likely due to differences in experimental conditions, particle type and timing [69]. In general, cytotoxic effects start to appear from concentrations of $25 \mu \mathrm{g} / \mathrm{mL}$ or higher in various lung, intestinal but also immune cell models. However, as was also demonstrated by our results, cytotoxicity is not always going hand in hand with a decreased barrier integrity, for which different mechanisms can be at play. Hindering cell proliferation and activation of apoptotic pathways has been shown in A549 cells [50] and murine and human lung organoids [63] and activation of such processes that impair cell growth might explain the lower TEER upon exposure to some of the MNP in the MucilAir ${ }^{\text {rix }}$ model. Additionally, lower TEER values can also indicate increased epithelial permeability for which ROS-induced disruption of tight junction proteins might be held responsible as they are well-known to disrupt tight junctions and to be formed upon interaction of MNP with the biological environment $[21,70]$. In congruence with the data presented here, MNP-associated release (or gene expression) of pro-inflammatory cytokines such as IL-6 and IL$1 \beta$ has been observed in several other in vitro studies [50, $53,55,70]$, but also in vivo in rat and mice [53, 54]. At the initiation of the inflammatory response, pro-inflammatory cytokines like IL-1 $\beta$, IL- 6 and IL-8 facilitate neutrophil recruitment. This recruitment of inflammatory cells upon MNP exposure might pursue particle clearance at first, but if sustained, e.g. upon repeated or continuous exposure to MNP and/or if the immune system fails to remove the particles, this will likely evoke tissue damage and increase the risk of neoplasia [71]. Despite the frequently reported observations on an activated pro-inflammatory immune response upon MNP exposure, there are also studies that did not find such inflammatory responses [20, $72,73]$. As different in vitro or in vivo models, MNP and exposure regimens are used in every study, different outcomes are inevitable. Nonetheless, MNP clearly have the potential to affect human health, but the exact impact and consequences on the long-term are currently unknown and need to be explored in future investigations.

\section{Conclusions}

Although not the first in demonstrating MNP-induced cytotoxicity or particle crossing of the lung and intestinal epithelial barrier, the innovative aspect of the current study was that we used advanced in vitro models representing the tissue architecture and cell type diversity in vivo. Our results showed the applicability of the presented lung and intestinal models for MNP research into 1) MNP-induced biological or biochemical responses of the exposed epithelium, and 2) penetration effects of the MNP themselves. Of course, results from the specific MNP should be interpreted with care, especially as the applied dose was relatively high. These achieved experimental outcomes fit the needs in MNP risk analysis, for which data on exposure and hazard are needed. Furthermore, with an expected higher in vitro-in vivo translatability compared to conventional in vitro research models, utilization of such advanced research models likely contribute to a more complete assessment of MNP impact. Further optimization and validation of the current methodologies should be part of future investigations, as well as the possibility to implement these advanced in vitro lung and gut epithelial barrier models in MNP risk analysis strategies.

\section{Abbreviations}

FD4: FITC-dextran 4 kDa; HDPE: high density polyethylene; IEBC: Intestinal explant barrier chip; LDH: Lactate dehydrogenase; MNP: Micro- and nanoplastics; OCU: Ocean cleanup; $P_{\text {app }}$ : Apparent permeability; PS: Polystyrene; PS-F: Fluorescently labeled polystyrene; PSD: Particle size descriptor; SEM: Scanning electron microscope; TEER: Transepithelial electrical resistance

\section{Supplementary Information}

The online version contains supplementary material available at https://doi. org/10.1186/s43591-021-00024-w.

\section{Additional file 1. Supplementary methods.}

Additional file 2: Supplementary Fig. 1 Characterization of microand nanoplastic particles by Micro Fourier Transform Infrared microscopy ( $\mu$-FTIR). Representative spectra of polystyrene (PS) spheres of $0.05,0.1,1$ and $10 \mu \mathrm{m}$, high density polyethylene (HDPE) fragments and the nylon fiber of $10 \times 30 \mu \mathrm{m}$.

Additional file 3: Supplemental Fig. 2 Functionality and viability of human and porcine intestinal tissue explants exposed to $0.1 \%$ Triton $X$ 100 or MNP ( $1 \mathrm{mg} / \mathrm{mL})$. A-C Human colon tissue explants were mounted in the InTESTine ${ }^{T M}$ and exposed to $0.1 \%$ Triton $X-100$ for $4 \mathrm{~h}(n=7$, two in dependent experiments). A Transport and ratio of antipyrine/atenolol (both applied at $10 \mu \mathrm{M}$ ) apparent permeability $\left(P_{\text {app }}\right)$, calculated between 1 and $4 \mathrm{~h}$ of incubation. Cutoff for proper tissue functionality is 2 , indicated by the dotted line. B Average permeability per hour of a large fluorescent molecule (FITC Dextran 4 kD; FD4) from the apical to the basolateral compartment between 0 and $4 \mathrm{~h}$. Cutoff for proper barrier integrity is $1 \% / \mathrm{h}$. C Cumulative LDH release into the apical and basolateral compartment. D-E Human colon tissue explants were mounted in the InTESTine $^{\mathrm{TM}}$ and exposed to MNP for $4 \mathrm{~h}(n=3)$. Mannitol (D) and caffeine (E) were co-administrated in all incubations $(10 \mu \mathrm{M})$ and the apparent permeability $\left(P_{\text {app }}\right.$ ) was calculated between 1 and 2 and $2-4 \mathrm{~h}$ of incubation. F-G Control and PS-F 10 exposed porcine colon tissue explants in the Intestinal Explant Barrier Chip (IEBC) for $24 \mathrm{~h}(n=4)$. Mannitol $(\mathbf{F})$ and caffeine $(\mathbf{G})$ were co-administrated in all incubations $(10 \mu \mathrm{M})$ and the $P_{\text {app }}$ was calculated between 3 and 5 and $22-24$ h of incubation. Data are presented as mean $\pm \mathrm{SD}$.

Additional file 4: Supplemental Fig. 3 Fluorescence microscopy images of apical and basolateral solutions of the PS-F incubations. A Representative images of the apical dose solutions of the fluorescent PS particles with size $0.05,1$ and $10 \mu \mathrm{m}(1 \mathrm{mg} / \mathrm{mL})$ and basolateral medium $5 \mathrm{~h}$ 
after exposure to porcine colon tissue in the InTESTine ${ }^{\text {TM }}$ platform. B Two close-ups of the PS-F 1 basolateral medium.

Additional file 5: Supplemental Fig. 4 Permeability of fluorescent MNP in porcine intestinal tissue. A-C Representative confocal microscopy images of blanc control and $5 \mathrm{~h}$ PS-F 1 or PS-F 10 exposed porcine ileum, colon and jejunum tissue explants. Dark blue: cell nuclei (DAPI); red: actin (phalloidin; cytoskeleton, intestinal/crypt linings); purple: cilia (acetylatedtubulin; cytoskeleton); light blue: MNP. Each staining is separately visualized with a specific laser in the blue, green, red or far-red channel, followed by projecting the signals from the separate channels in an overlay picture. A lleum and colon tissue were imaged using a 10x objective. As the complete intestinal tissue segment (from apical to basolateral) did not fit in one field of view (FOV) using the 10x objective, 2 or 3 FOVs per slide were taken and combined into one image. B lleum and colon tissue exposed to PS-F 1 and PS-F 10 were imaged using a 40x and 100x objective. C. Close-ups and overlay of the separate visualizations for DAPI, phalloidin and in jejunum tissue exposed to PS-F 10.

\section{Acknowledgements}

The authors thank Thijs Nijdam for his contribution to the MNP selection and SEM analyses, Heleen Lanters for preparation of the MNP, Esmée Wierenga for the fluorescent microscopy on the PS-F particles in apical and basolateral medium, Wilma Middel for project control, Dick Vethaak for providing the PS and HDPE particles, Nanda Keijzer for cryosectioning and Anna Akhmanova for coordinating the immunohistochemistry and confocal microscopy work.

\section{Authors' contributions}

JMD, EH, IG and LW carried out experiments, under supervision of EvdS and IMK. BNM provided the nylon fibers and supernatant, BvdZ provided the PS and HDPE particles. JMD carried out statistics and prepared Figs. JMD, EvdS and IMK developed the study concept and design. Drafting and initial review of the manuscript were performed by JMD, EH, IG, LW, BNM, BvdZ, EvdS, IMK. All authors were involved in analysis and interpretation of data and have read and approved the manuscript

\section{Funding}

This work was financially supported by grants of the ZonMw Microplastics \& Health subsidy round, with application numbers 40-45800-98-117 and 4045800-98-109, with additional funding from ETH inside Microplastics \& Health call with application numbers 40-45800-98-206 and 40-45800-98-205.

\section{Availability of data and materials}

All data generated or analysed during this study are included in this published article and its supplementary information files.

\section{Declarations}

\section{Competing interests}

The authors declare that they have no competing interest.

\section{Author details}

${ }^{1}$ Department of Metabolic Health Research, the Netherlands Organization for Applied Scientific Research (TNO), Zeist, The Netherlands. ${ }^{2}$ Department of Environmental Modelling, Sensing \& Analysis, TNO, Utrecht, The Netherlands. ${ }^{3}$ Division of Cell Biology, Neurobiology and Biophysics, Department of Biology, Faculty of Science, Utrecht University, Utrecht, The Netherlands. ${ }^{4}$ Department of Molecular Pharmacology, Groningen Research Institute of Pharmacy, University of Groningen, Groningen, The Netherlands. ${ }^{5}$ University Medical Center Groningen, Groningen Research Institute of Asthma and COPD, University of Groningen, Groningen, The Netherlands. 'Deltares, Delft, The Netherlands.

Received: 4 August 2021 Accepted: 20 December 2021

Published online: 28 January 2022

\section{References}

1. PlasticsEurope. Plastics - the Facts 2019. Vol. 8, www.plasticseurope.org. 2019. p. IV.
2. Frias JPGL, Nash R. Microplastics: finding a consensus on the definition. Mar Pollut Bull. 2019;138(September 2018):145-7. https://doi.org/10.1016/j.ma rpolbul.2018.11.022.

3. Ekvall MT, Lundqvist M, Kelpsiene E, Šileikis E, Gunnarsson SB, Cedervall T. Nanoplastics formed during the mechanical breakdown of daily-use polystyrene products. Nanoscale Adv. 2019;1(3):1055-61. https://doi.org/10.1 039/C8NA00210J.

4. Hartmann NB, Hüffer T, Thompson RC, Hassellöv M, Verschoor A, Daugaard $A E$, et al. Are we speaking the same language? Recommendations for a definition and categorization framework for plastic debris. Environ Sci Technol. 2019;53(3):1039-47. https://doi.org/10.1021/acs.est.8b05297.

5. Liebezeit G, Liebezeit E. Non-pollen particulates in honey and sugar. Food Addit Contam Part A Chem Anal Control Expo Risk Assess. 2013;30(12): 2136-40. https://doi.org/10.1080/19440049.2013.843025.

6. Liebezeit $\mathrm{G}$, Liebezeit E. Synthetic particles as contaminants in German beers. Food Addit Contam - Part A Chem Anal Control Expo Risk Assess. 2014;31(9):1574-8. https://doi.org/10.1080/19440049.2014.945099.

7. Yang D, Shi H, Li L, Li J, Jabeen K, Kolandhasamy P. Microplastic pollution in table salts from China. Environ Sci Technol. 2015;49(22):13622-7. https://doi. org/10.1021/acs.est.5b03163.

8. Li J, Yang D, Li L, Jabeen $\mathrm{K}$, Shi H. Microplastics in commercial bivalves from China. Environ Pollut. 2015;207:190-5. https://doi.org/10.1016/j.envpol.2015. 09.018 .

9. Van Cauwenberghe $L$, Janssen CR. Microplastics in bivalves cultured for human consumption. Environ Pollut. 2014;193:65-70. https://doi.org/10.101 6/j.envpol.2014.06.010

10. Mathalon A, Hill P. Microplastic fibers in the intertidal ecosystem surrounding Halifax Harbor. Nova Scotia Mar Pollut Bull. 2014;81(1):69-79. https://doi.org/10.1016/j.marpolbul.2014.02.018.

11. Woodall LC, Sanchez-Vidal A, Canals M, Paterson GLJ, Coppock R, Sleight V, et al. The deep sea is a major sink for microplastic debris. R Soc Open Sci. 2014;1(4):140317.

12. Eriksen M, Lebreton LCM, Carson HS, Thiel M, Moore CJ, Borerro JC, et al. Plastic pollution in the World's oceans: more than 5 trillion plastic pieces weighing over 250,000 tons afloat at sea. PLoS One. 2014;9(12):1-15. https:// doi.org/10.1371/journal.pone.0111913.

13. Cai L, Wang J, Peng J, Tan Z, Zhan Z, Tan X, et al. Characteristic of microplastics in the atmospheric fallout from Dongguan city, China: preliminary research and first evidence. Environ Sci Pollut Res. 2017;24(32): 24928-35. https://doi.org/10.1007/s11356-017-0116-x.

14. Koelmans B, Pahl S, Backhaus T, Bessa F, van Calster G, Contzen N, et al. A scientific perspective on microplastics in nature and society. Evidence Rev Rep. 2019;2019:176. https://doi.org/10.26356/microplastics.

15. Rahman A, Sarkar A, Yadav OP, Achari G, Slobodnik J. Potential human health risks due to environmental exposure to nano- and microplastics and knowledge gaps: a scoping review. Sci Total Environ [internet]. 2021;757: 143872. Available from. https://doi.org/10.1016/j.scitotenv.2020.143872.

16. Wright SL, Kelly FJ. Plastic and human health: a Micro issue? Environ Sci Technol. 2017;51(12):6634-47. https://doi.org/10.1021/acs.est.7b00423.

17. Vethaak AD, Legler J. Microplastics and human health. Science (80- ). 2021; 371(6530):672-4.

18. Ragusa A, Svelato A, Santacroce C, Catalano P, Notarstefano V, Carnevali O, et al. Plasticenta: first evidence of microplastics in human placenta. Environ Int. 2021;146:106274. https://doi.org/10.1016/j.envint.2020.106274.

19. Schwabl P, Koppel $S$, Konigshofer $P$, Bucsics $T$, Trauner $M$, Reiberger $T$, et al. Detection of various microplastics in human stool: a prospective case series. Ann Intern Med. 2019;171(7):453-7. https://doi.org/10.7326/M19-0618.

20. Stock V, Böhmert L, Lisicki E, Block R, Cara-Carmona J, Pack LK, et al. Uptake and effects of orally ingested polystyrene microplastic particles in vitro and in vivo. Arch Toxicol. 2019;93(7):1817-33. https://doi.org/10.1007/s00204-01 9-02478-7.

21. Rubio L, Marcos R, Hernández A. Potential adverse health effects of ingested micro- and nanoplastics on humans. Lessons learned from in vivo and in vitro mammalian models. J Toxicol Environ Heal - Part B Crit Rev. 2020; 23(2):51-68. https://doi.org/10.1080/10937404.2019.1700598.

22. Kooter IM, Gröllers-Mulderij M, Duistermaat E, Kuper F, Schoen ED. Factors of concern in a human 3D cellular airway model exposed to aerosols of nanoparticles. Toxicol Vitr. 2017;44(December 2016):339-48. https://doi.org/1 0.1016/j.tiv.2017.07.006

23. Kooter I, Ilves M, Gröllers-Mulderij M, Duistermaat E, Tromp PC, Kuper F, et al. Molecular signature of asthma-enhanced sensitivity to $\mathrm{CuO}$ 
nanoparticle aerosols from 3D cell model. ACS Nano. 2019;13(6):6932-46. https://doi.org/10.1021/acsnano.9b01823.

24. Westerhout J, Van De Steeg E, Grossouw D, Zeijdner EE, Krul CAM, Verwei $M$, et al. A new approach to predict human intestinal absorption using porcine intestinal tissue and biorelevant matrices. Eur J Pharm Sci. 2014;63: 167-77. https://doi.org/10.1016/j.ejps.2014.07.003.

25. Stevens $\amalg$, van Lipzig MMH, Erpelinck SLA, Pronk A, van Gorp J, Wortelboer HM, et al. A higher throughput and physiologically relevant twocompartmental human ex vivo intestinal tissue system for studying gastrointestinal processes. Eur J Pharm Sci. 2019;137(February):104989. https://doi.org/10.1016/j.ejps.2019.104989.

26. Eslami Amirabadi $H$, Donkers J, Wierenga E, Ingenhut B, Pieters L, Stevens $L$, et al. Intestinal explant barrier Chip: long-term intestinal absorption screening in a novel microphysiological system using tissue explants. Lab Chip. 2021. https://doi.org/10.1039/d1lc00669j.

27. Li M, Wilkinson D, Patchigolla K. Comparison of particle size distributions measured using different techniques. Part Sci Technol. 2005;23(3):265-84. https://doi.org/10.1080/02726350590955912.

28. Allen M, Millett P, Dawes E, Rushton N. Lactate dehydrogenase activity as a rapid and sensitive test for the quantification of cell numbers in vitro. Clin Mater. 1994;16(4):189-94. https://doi.org/10.1016/0267-6605(94)90116-3.

29. Dawson A, Dyer C, Macfie J, Davies J, Karsai L, Greenman J, et al. A microfluidic chip based model for the study of full thickness human intestinal tissue using dual flow. Biomicrofluidics. 2016;10(6).

30. Srinivasan B, Kolli AR, Esch MB, Abaci HE, Shuler ML, Hickman JJ. TEER measurement techniques for in vitro barrier model systems. J Lab Autom. 2015;20(2):107-26. https://doi.org/10.1177/2211068214561025.

31. FDA. Waiver of In Vivo Bioavailability and Bioequivalence Studies for Immediate-Release Solid Oral Dosage Forms Based on a Biopharmaceutics Classification System. In: Handbook of Pharmaceutical Manufacturing Formulations. Third ed. Rockville, MD; 2020. p. 27-35.

32. Vaessen SFC, van Lipzig MMH, Pieters RHH, Krul CAM, Wortelboer HM, van de Steeg E. Regional expression levels of drug transporters and metabolizing enzymes along the pig and human intestinal tract and comparison with Caco-2 cells. Drug Metab Dispos. 2017;45(4):353-60. https://doi.org/10.1124/dmd.116.072231.

33. Patterson JK, Lei XG, Miller DD. The pig as an experimental model for elucidating the mechanisms governing dietary influence on mineral absorption. Exp Biol Med. 2008;233(6):651-64. https://doi.org/10.3181/0709MR-262.

34. Westerhout J, Wortelboer H, Verhoeckx K. Ussing chamber. In: The impact of food bioactives on health. Cham: Springer International Publishing; 2015. p. 263-73.

35. Herrmann JR, Turner JR. Beyond Ussing's chambers: contemporary thoughts on integration of transepithelial transport. Am J Physiol Physiol. 2016;310(6): C423-31. https://doi.org/10.1152/ajpcell.00348.2015.

36. Stevens $\sqcup$, van Lipzig MMH, Erpelinck SLA, Pronk A, van Gorp J, Wortelboer HM, et al. A higher throughput and physiologically relevant twocompartmental human ex vivo intestinal tissue system for studying gastrointestinal processes. Eur J Pharm Sci. 2019;137(July):104989. https:// doi.org/10.1016/..ejps.2019.104989.

37. Westerhout J, Van De Steeg E, Grossouw D, Zeijdner EE, Krul CAM, Verwei $M$, et al. A new approach to predict human intestinal absorption using porcine intestinal tissue and biorelevant matrices. Eur J Pharm Sci. 2014;63: 167-77. https://doi.org/10.1016/j.jps.2014.07.003.

38. Donkers JM, Amirabadi HE, van de Steeg E. Intestine-on-a-chip: next level in vitro research model of the human intestine. Curr Opin Toxicol. 2020;135907.

39. Baydoun M, Treizeibré A, Follet J, Vanneste SB, Creusy C, Dercourt L, et al. An interphase microfluidic culture system for the study of ex vivo intestinal tissue. Micromachines. 2020;11(2).

40. Costa MO, Nosach R, Harding JCS. Development of a 3D printed device to support long term intestinal culture as an alternative to hyperoxic chamber methods. 3D Print Med. 2017;3(1):0-4

41. Hirt N, Body-Malapel M. Immunotoxicity and intestinal effects of nano- and microplastics: a review of the literature. Part Fibre Toxicol. 2020;17(1):1-22. https://doi.org/10.1186/s12989-020-00387-7.

42. EFSA. Presence of microplastics and nanoplastics in food, with particular focus on seafood. EFSA J. 2016;14(6).

43. Cox KD, Covernton GA, Davies HL, Dower JF, Juanes F, Dudas SE. Human consumption of microplastics. Environ Sci Technol. 2019;53(12):7068-74. https://doi.org/10.1021/acs.est.9b01517.
44. Rochman CM, Tahir A, Williams SL, Baxa DV, Lam R, Miller JT, et al. Anthropogenic debris in seafood: plastic debris and fibers from textiles in fish and bivalves sold for human consumption. Sci Rep. 2015;5(August):110. https://doi.org/10.1038/srep14340.

45. Bouwmeester H, Hollman PCH, Peters RJB. Potential health impact of environmentally released Micro- and Nanoplastics in the human food production chain: experiences from Bouwmeester, H., Hollman, P. C. H., \& Peters, R. J. B. (2015). Potential health impact of environmentally released Micro- and. Environ Sci Technol. 2015;49(15):8932-47. https://doi.org/10.1 021/acs.est.5b01090.

46. Dris R, Gasperi J, Saad M, Mirande C, Tassin B. Synthetic fibers in atmospheric fallout: a source of microplastics in the environment? Mar Pollut Bull. 2016;104(1-2):290-3. https://doi.org/10.1016/j.marpolbul.2016.01. 006.

47. Kasirajan S, Ngouajio M. Polyethylene and biodegradable mulches for agricultural applications: a review. Agron Sustain Dev. 2012;32(2):501-29. https://doi.org/10.1007/s13593-011-0068-3.

48. Burkhart J, Jones W, Porter DW, Washko RM, Eschenbacher WL, Castellan RM. Hazardous occupational exposure and lung disease among nylon flock workers. Am J Ind Med. 1999;36(SUPPL. 1):145-6. https://doi.org/10.1002/ (SICI) 1097-0274(199909)36:1+<145::AID-AJIM51>3.0.CO;2-F.

49. Panko JM, Kreider ML, McAtee BL, Marwood C. Chronic toxicity of tire and road wear particles to water- and sediment-dwelling organisms. Ecotoxicology. 2013;22(1):13-21. https://doi.org/10.1007/s10646-012-0998-9.

50. Xu M, Halimu G, Zhang Q, Song Y, Fu X, Li Y, et al. Internalization and toxicity: a preliminary study of effects of nanoplastic particles on human lung epithelial cell. Sci Total Environ. 2019;694:133794. https://doi.org/10.101 6/j.scitotenv.2019.133794

51. Varela JA, Bexiga MG, Åberg C, Simpson JC, Dawson KA. Quantifying sizedependent interactions between fluorescently labeled polystyrene nanoparticles and mammalian cells. J Nanobiotechnol. 2012;10(1):39. https:// doi.org/10.1186/1477-3155-10-39.

52. Powell JJ, Faria N, Thomas-McKay E, Pele LC. Origin and fate of dietary nanoparticles and microparticles in the gastrointestinal tract. J Autoimmun. 2010;34(3):J226-33. https://doi.org/10.1016/j.jaut.2009.11.006.

53. Brown DM, Wilson MR, MacNee W, Stone V, Donaldson K. Size-dependent proinflammatory effects of ultrafine polystyrene particles: a role for surface area and oxidative stress in the enhanced activity of ultrafines. Toxicol Appl Pharmacol. 2001;175(3):191-9. https://doi.org/10.1006/taap.2001.9240.

54. Deng $Y$, Zhang $Y$, Lemos $B$, Ren $\mathrm{H}$. Tissue accumulation of microplastics in mice and biomarker responses suggest widespread health risks of exposure. Sci Rep. 2017;7(April):1-10. https://doi.org/10.1038/srep46687.

55. Hwang J, Choi D, Han S, Jung SY, Choi J, Hong J. Potential toxicity of polystyrene microplastic particles. Sci Rep. 2020;10(1):1-12.

56. Choi D, Bang J, Kim T, Oh Y, Hwang Y, Hong J. in vitro Chemical and physical toxicity of polystyrene microplastics in human-derived cells. 2020. $1-41 \mathrm{p}$.

57. Lehner R, Wohlleben W, Septiadi D, Landsiedel R, Petri-Fink A, RothenRutishauser B. A novel 3D intestine barrier model to study the immune response upon exposure to microplastics. Arch Toxicol. 2020;94(7):2463-79. https://doi.org/10.1007/s00204-020-02750-1.

58. Magrì D, Sánchez-Moreno P, Caputo G, Gatto F, Veronesi M, Bardi G, et al. Laser ablation as a versatile tool to mimic polyethylene terephthalate nanoplastic pollutants: characterization and toxicology assessment. ACS Nano. 2018;12(8):7690-700. https://doi.org/10.1021/acsnano.8b01331.

59. Winton HL, Wan H, Cannell MB, Gruenert DC, Thompson PJ, Garrod DR, et al. Cell lines of pulmonary and non-pulmonary origin as tools to study the effects of house dust mite proteinases on the regulation of epithelial permeability. Clin Exp Allergy. 1998;28(10):1273-85. https://doi.org/10.1046/ j.1365-2222.1998.00354.X.

60. Cooney DJ, Hickey AJ. Cellular response to the deposition of diesel exhaust particle aerosols onto human lung cells grown at the air-liquid interface by inertial impaction. Toxicol Vitr. 2011;25(8):1953-65. https://doi.org/10.1016/j. tiv.2011.06.019.

61. Kreyling WG, Semmler-Behnke M, Seitz J, Scymczak W, Wenk A, Mayer P, et al. Size dependence of the translocation of inhaled iridium and carbon nanoparticle aggregates fürom the lung of rats to the blood and secondary target organs. Inhal Toxicol. 2009;21(SUPPL. 1):55-60. https://doi.org/10.1 080/08958370902942517.

62. Kreyling W, Semmler M, Erbe F, Mayer P, Takenaka S, Schulz H, et al. Translocation of ultrafine insoluble iridium particles from lung epithelium to 
extrapulmonary organs is size dependent but very low. Journal of Toxicology and Environmental Health. Part A, 2002;65(20):1513-30. https:// doi.org/10.1080/00984100290071649.

63. van Dijk F, Song S, van Eck GW, Wu X, Bos IST, Boom DHA, et al. Inhalable textile microplastic fibers impair airway epithelial growth. bioRxiv. 2021; (January):2021.01.25.428144.

64. Wik A. Toxic components leaching from tire rubber. Bull Environ Contam Toxicol. 2007;79(1):114-9. https://doi.org/10.1007/s00128-007-9145-3.

65. Capolupo M, Sørensen L, Jayasena KDR, Booth AM, Fabbri E. Chemical composition and ecotoxicity of plastic and car tire rubber leachates to aquatic organisms. Water Res [internet]. 2020;169:115270. Available from. https://doi.org/10.1016/j.watres.2019.115270.

66. Martínez-Gómez C, León VM, Calles S, Gomáriz-Olcina M, Vethaak AD. The adverse effects of virgin microplastics on the fertilization and larval development of sea urchins. Mar Environ Res. 2017;130:69-76. https://doi. org/10.1016/j.marenvres.2017.06.016.

67. Björnsdotter M. Leaching of residual monomers, oligomers and additives from polyethylene, polypropylene, polyvinyl chloride, high-density polyethylene and polystyrene virgin plastics [internet]: Örebro University, School of Science and Technology; 2015. Available from: https://www.divaportal.org/smash/record.jsf?pid=diva2\%3A855478\&dswid=4786. Accessed 7 Dec 2021.

68. Polysciences Inc. Safety Data Sheet Polystyrene spheres [Internet]. 2017. p. 3 Available from: https://www.polysciences.com/media/amasty/amfile/attach/ paryT5xrwqWszJcmdaf3wP6nhcEc980C.pdf. Accessed 7 Dec 2021

69. Banerjee A, Shelver WL. Micro- and nanoplastic induced cellular toxicity in mammals: a review. Sci Total Environ. 2021;755(Pt 2):142518. https://doi. org/10.1016/j.scitotenv.2020.142518

70. Shi Q, Tang J, Wang L, Liu R, Giesy JP. Combined cytotoxicity of polystyrene nanoplastics and phthalate esters on human lung epithelial A549 cells and its mechanism. Ecotoxicol Environ Saf. 2021;213:112041. https://doi.org/10.1 016/j.ecoenv.2021.112041.

71. Prata JC, da Costa JP, Lopes I, Duarte AC, Rocha-Santos T. Environmental exposure to microplastics: an overview on possible human health effects. Sci Total Environ. 2020;702:134455. https://doi.org/10.1016/j.scitotenv.201 9.134455 .

72. Sinnecker H, Krause T, Koelling S, Lautenschläger I, Frey A. The gut wall provides an effective barrier against nanoparticle uptake. Beilstein J Nanotechnol. 2014;5(1):2092-101. https://doi.org/10.3762/bjnano.5.218

73. Walczak AP, Hendriksen PJM, Woutersen RA, van der Zande M, Undas AK, Helsdingen $\mathrm{R}$, et al. Bioavailability and biodistribution of differently charged polystyrene nanoparticles upon oral exposure in rats. J Nanopart Res. 2015; 17(5):1-13. https://doi.org/10.1007/s11051-015-3029-y.

\section{Publisher's Note}

Springer Nature remains neutral with regard to jurisdictional claims in published maps and institutional affiliations.

\section{Submit your manuscript to a SpringerOpen ${ }^{\circ}$ journal and benefit from:}

- Convenient online submission

- Rigorous peer review

- Open access: articles freely available online

- High visibility within the field

- Retaining the copyright to your article

Submit your next manuscript at $\boldsymbol{\nabla}$ springeropen.com 